\title{
Conformational study of sarcosine as probed by matrix-isolation FT-IR spectroscopy and molecular orbital calculations
}

\author{
A. Gómez-Zavagliaa, ${ }^{a, b}$ R. Fausto ${ }^{a, *}$ \\ ${ }^{a}$ Department of Chemistry, University of Coimbra, P-3004-535 Coimbra, Portugal \\ ${ }^{\mathrm{b}}$ Facultad de Farmacia y Bioquímica, Universidad de Buenos Aires, RA-1113 Buenos Aires, Argentina
}

Received 14 May 2003; received in revised form 11 July 2003; accepted 11 July 2003

\begin{abstract}
Sarcosine ( $N$-methylglycine) has been studied by matrix-isolation FT-IR spectroscopy and molecular orbital calculations undertaken at the DFT/B3LYP and MP2 levels of theory with the 6-311++G(d,p) and 6-31++G(d,p) basis set, respectively. Eleven different conformers were located in the potential energy surface (PES) of sarcosine, with the ASC conformer being the ground conformational state. This form is analogous to the glycine most stable conformer and is characterized by a $\mathrm{NH} \cdots \mathrm{O}=$ intramolecular hydrogen bond; in this form, the carboxylic group assumes the cis configuration and the $\mathrm{O}=\mathrm{C}-\mathrm{C}-\mathrm{N}$ and $\mathrm{Lp}-\mathrm{N}-\mathrm{C}-\mathrm{C}$ (where $\mathrm{Lp}$ is the nitrogen lone electron pair) dihedral angles are ca. 15 and $-8^{\circ}$, respectively. The second most stable conformer $\left(\mathrm{G}^{\prime} \mathrm{AT}\right)$ exhibits a strong $\mathrm{OH} \cdots \mathrm{N}$ intramolecular hydrogen bond and a trans carboxylic group, being similar to the most stable form of $N, N$-dimethylglycine. These two forms were predicted to differ in energy by less than ca. $2 \mathrm{~kJ} \mathrm{~mol}^{-1}$ and represent $\approx 70 \%$ of the conformational population at room temperature. In consonance with the theoretical predictions, the FT-IR spectra of the matrix-isolated compound reveal the presence in the gaseous phase of the four conformers of sarcosine with experimentally accessible populations: besides conformers ASC and G'AT, forms GSC and AAC could also be identified experimentally. The assignment of the spectra of the different experimentally observed conformers of sarcosine was carried out. (C) 2003 Elsevier B.V. All rights reserved.
\end{abstract}

Keywords: Sarcosine; Matrix-isolation FT-IR; Molecular orbital

\section{Introduction}

Sarcosine ( $N$-methylglycine) belongs to the family of $N$-methylated derivatives of glycine, which also includes DMG ( $N, N$-dimethylglycine) and betaine $(N, N, N$-trimethylglycine $)$ as members. These molecules are known to affect the melting behavior of proteins and nucleic acids, and are also known as osmoprotectants or osmolytes [1-4]. They are produced in organisms and cellular systems that have

\footnotetext{
* Corresponding author.

E-mail address: rfausto@ci.uc.pt (R. Fausto).
}

adapted to extreme environmental conditions, such as high temperatures, very low humidity and high salinity $[1,2]$. These molecules lend protection to proteins against such denaturing stresses, without interfering with their functionality. It is believed that this compatibility results from the absence of interactions between osmolytes and substrates or cofactors [5].

The cryoprotective properties of this family of compounds were also the aim of several studies In fact, it was demonstrated that sarcosine, in concentrations greater than $1 \mathrm{M}$, reduces fusion and leakage of liposomes after freeze-thaw, by interacting with the acyl chains of the lipid bilayer [5-8]. 
From a strict chemical point of view, theoretical calculations have been used successfully to analyze relative energies and geometries of the conformers of a fairly large number of aminoacids (see, for example $[9,10])$. Concerning the chemical family of $N$-methylated aminoacids, in a previous study we have investigated DMG by a combined theoretical (DFT and MP2) and matrix-isolation FT-IR spectroscopic approach [11]. In that study, the spectral signatures of the three lowest energy conformers of neutral monomeric DMG were characterized. The conformational ground state was found to be the intramolecularly $\mathrm{O}-\mathrm{H} \cdots \mathrm{N}$ hydrogen-bonded GAT form, where the $\mathrm{Lp}-\mathrm{N}-\mathrm{C}-\mathrm{C}$ and $\mathrm{N}-\mathrm{C}-\mathrm{C}=\mathrm{O}$ dihedral angles are 30 and ca. $180^{\circ}$, respectively, and the carboxylic group assumes the trans configuration. In the second (ASC) and third (GSC) lowest energy forms of DMG, the carboxylic moiety assumes the cis conformation, while the $\mathrm{N}-\mathrm{C}-\mathrm{C}=\mathrm{O}$ axis adopts the syn arrangement and the conformation around the $\mathrm{N}-\mathrm{C}$ bond is, respectively, anti and gauche. Very interestingly, DMG has been shown to be a paradigmatic example of a molecule exhibiting conformer selective aggregation, with the ASC conformer showing a considerably larger tendency to aggregate than the remaining experimentally detected conformers [11].

Sarcosine was studied theoretically before at the ab initio restricted Hartree-Fock level of theory with the 6-311++G(d, p) basis set (or lower), complemented with single point MP2 calculations carried out using the same basis and the RHF/6-311++G(d, p) optimized geometries [12]. In that study, the most stable conformer of sarcosine was found to be characterized by having an $\mathrm{NH} \cdots \mathrm{O}=\mathrm{C}$ intramolecular hydrogen bond, such as previously found for glycine [9]. At the highest level of theory used [12], the second most stable form was found to be a conformer with a $\mathrm{OH} \cdots \mathrm{N}$ intramolecular hydrogen bond, similar to the lowest energy conformer of DMG [11]. The neutral (non-ionic) versus zwitterionic form tautomerism in sarcosine was also investigated theoretically [13], with the zwitterionic form being predicted to be higher energy than the neutral species, in the gaseous phase, by more than $135 \mathrm{~kJ} \mathrm{~mol}^{-1}$.

The structure of crystalline sarcosine at $135 \mathrm{~K}$ was determined by X-ray diffraction by Mostad and Natarajan [14]. It was found that, in the crystal, sarcosine exists exclusively in the zwitterionic state and that the four molecules constituting the crystal unit cell are in an extended form with a small deviation from planarity in the $\alpha$-aminoacid group $(\mathrm{C}-\mathrm{C}-\mathrm{N}-\mathrm{C}$ dihedral angle equal to $-166.3^{\circ}$ ) as well as in the main chain $\left(\mathrm{O}=\mathrm{C}-\mathrm{C}-\mathrm{N}\right.$ dihedral angle equal to $\left.-6.8^{\circ}\right)$. On the other hand, no experimental structural or conformational studies have been undertaken previously on sarcosine either in the gaseous phase or for the isolated molecule. In addition, to the best of our knowledge no vibrational data on sarcosine have been reported hitherto.

Following the lines of our previous studies on glycine [9] and DMG [11], in this study we used matrix-isolation FT-IR spectroscopy, supported by high level DFT and MP2 calculations, to undertake the conformational and vibrational characterization of neutral sarcosine.

\section{Materials and methods}

\subsection{Matrix-isolation FT-IR spectroscopy}

Sarcosine was obtained from Aldrich (purity 99\%). In the matrix-isolation experiments, a glass vacuum system and standard manometric procedures were used to deposit the matrix gas (argon N60, obtained from Air Liquid). Matrices were prepared by co-deposition onto a cooled CsI substrate of the matrix gas and sarcosine sublimated from a specially designed temperature variable mini-oven assembled inside the cryostat. Data collection was performed on a Mattson (Infinity 60AR Series) with $0.5 \mathrm{~cm}^{-1}$ spectral resolution. All experiments were done on the basis of an APD Cryogenics close-cycle helium refrigeration system with a DE-202A expander. Necessary modifications of the sample compartment of the spectrometer were made in order to accommodate the cryostat head and allow efficient purging of the instrument by a stream of dry air to remove water and $\mathrm{CO}_{2}$ vapors. After depositing the compound, annealing experiments were performed until a temperature of $20 \mathrm{~K}$.

\subsection{Computational methods}

The quantum chemical calculations were performed with Gaussian 98 (Revision A.9) [15] at the DFT and 
MP2 levels of theory, using the $6-311++\mathrm{G}(\mathrm{d}, \mathrm{p})$ and $6-31++\mathrm{G}(\mathrm{d}, \mathrm{p})$ basis sets, respectively $[16,17]$. Since it is well known that in general for MP2 calculations the change from $6-31++\mathrm{G}(\mathrm{d}, \mathrm{p})$ to $6-311++\mathrm{G}(\mathrm{d}, \mathrm{p})$ does not improve very much the quality of the results, the smaller basis set was selected for these calculations, in order to reduce the necessary computational time. The DFT calculations were carried out with the three-parameter density functional abbreviated as B3LYP, which includes Becke's gradient exchange correction [18] the Lee et al. correlation functional [19] and the Vosko et al. correlation functional [20]. Conformations were optimized at each level of theory using the Geometry Direct Inversion of the Invariant Subspace (GDIIS) method [21]. Vibrational frequencies were calculated at each level of theory and the nature of the critical points on the potential energy surface (PES) resulting from optimization was determined by inspection of the corresponding calculated Hessian matrix, all structures confirmed to be minimum energy conformations. The calculated frequencies were scaled down by a single factor $(0.978)$ to correct them for the effects of basis set limitations, neglected part of electron correlation and anharmonicity effects, and used to assist the analysis of the experimental spectra and to account for the zero-point vibrational energy contribution to the total energy. Normal coordinates analyses were undertaken in the internal coordinates space as described by Schachtschneider [22] using the program BALGA and the optimized geometries and harmonic force constants resulting from the DFT/B3LYP calculations. Potential energy profiles for internal rotation were calculated performing a relaxed scan on the potential energy surface along the reaction coordinate and the transition state structures for conformational interconversion obtained using the Synchronous Transit-Guided Quasi-Newton (STQN) method [23].

\section{Results and discussion}

\subsection{Geometries and energies}

The neutral (non-ionic) form of sarcosine, as glycine and DMG, has three different internal rotation axes that can give rise to conformational isomers ( $\mathrm{Lp}-\mathrm{N}-\mathrm{C}-\mathrm{C}, \mathrm{N}-\mathrm{C}-\mathrm{C}=\mathrm{O}$ and $\mathrm{O}=\mathrm{C}-\mathrm{O}-\mathrm{H}$; $\mathrm{Lp}$ is the lone electron pair of nitrogen atom). However, the molecule of sarcosine has a lower intrinsic symmetry than both glycine and DMG: it shows a chyral nitrogen atom and all of its possible conformations belong to the $\mathrm{C}_{1}$ symmetry point group. In addition, contrarily to DMG (but as for glycine), in sarcosine intramolecular hydrogen bonding can also involve the hydrogen amine atom. Thus, it could be expected that the conformational space of sarcosine is considerably more complex than those of glycine and DMG. Indeed, for each one of the two spectroscopically (and energetically) equivalent arrangements around the nitrogen atom sarcosine may exist in 11 different conformational states. Table 1 presents the DFT and MP2 calculated relative energies for all the possible conformers of sarcosine, which are depicted in Fig. 1. The calculated structural parameters for the five most stable conformers are provided in Table 2. ${ }^{1}$

The large conformational flexibility of sarcosine can be easily noticed taking into consideration that there are six conformers differing in energy by less than $8 \mathrm{~kJ} \mathrm{~mol}^{-1}$. All these forms exhibit an intramolecular hydrogen bond. The most stable conformer (ASC), as well as the third conformer in the scale of relative energies (GSC), show the relatively strong $\mathrm{N}-\mathrm{H} \cdots \mathrm{O}=$ hydrogen bond. These forms are similar to the most stable conformer of glycine. They differ only in the conformation around the $\mathrm{C}-\mathrm{N}$ bond, having their carboxylic group in the usually most stable conformation $\left(\mathrm{O}=\mathrm{C}-\mathrm{O}-\mathrm{H} \approx 0^{\circ}\right.$; cis) [24-26]. Form GSC is predicted by the DFT calculations to be only $1.44 \mathrm{~kJ} \mathrm{~mol}^{-1}$ (MP2: $2.02 \mathrm{~kJ} \mathrm{~mol}^{-1}$ ) higher in energy than the conformational ground state. The DFT energy barrier separating these two forms was also predicted to be low $\left(\Delta E_{\mathrm{GSC} \rightarrow \mathrm{ASC}}=5.15 \mathrm{~kJ} \mathrm{~mol}^{-1}\right.$; Fig. 2). The second $\left(\mathrm{G}^{\prime} \mathrm{AT}\right)$ and the fourth (GAT) most stable conformers of sarcosine exhibit a strong $\mathrm{OH} \cdots \mathrm{N}$ hydrogen bond, being similar to the most stable conformer of DMG [11]. In these two conformers, the presence of the strong $\mathrm{OH} \cdots \mathrm{N}$ hydrogen bond compensates the increase in energy associated with the energetically less favored trans conformation of the carboxylic group $\left(\mathrm{O}=\mathrm{C}-\mathrm{O}-\mathrm{H} \approx 180^{\circ}\right)$. Note that all the remaining conformers bearing a trans carboxylic group (AST, G'ST, GST, see Fig. 1 and Table 1)

\footnotetext{
${ }^{1}$ Data for the higher energy conformers can be obtained from the corresponding author (rfausto@ci.uc.pt).
} 
Table 1

Relative energies $\left(\Delta E_{\mathrm{ZPE}}\right)$, including zero-point vibrational contributions and dipole moments $(\mu)$, for the various conformers of sarcosine ${ }^{\mathrm{a}}$

\begin{tabular}{|c|c|c|c|c|}
\hline \multirow[t]{2}{*}{ Conformer } & \multicolumn{2}{|l|}{$\Delta E_{\mathrm{ZPE}}$} & \multicolumn{2}{|l|}{$\mu$} \\
\hline & DFT(B3LYP)/6-311++G(d, p) & $\mathrm{MP} 2 / 6-31++\mathrm{G}(\mathrm{d}, \mathrm{p})^{\mathrm{b}}$ & DFT & MP2 \\
\hline ASC & $0.0(-849969.0617)^{\mathrm{c}}$ & $0.0(-847338.6337)^{\mathrm{c}}$ & 1.02 & 1.05 \\
\hline $\mathrm{G}^{\prime} \mathrm{AT}$ & 1.32 & 2.02 & 5.73 & 5.67 \\
\hline GSC & 1.44 & 3.39 & 1.75 & 1.77 \\
\hline GAT & 3.23 & 5.39 & 5.73 & 5.71 \\
\hline AAC & 4.72 & 3.44 & 1.85 & 1.72 \\
\hline GAC & 6.90 & 7.15 & 2.36 & 2.40 \\
\hline $\mathrm{G}^{\prime} \mathrm{SC}$ & 8.50 & 9.14 & 1.75 & 2.25 \\
\hline $\mathrm{G}^{\prime} \mathrm{AC}$ & 12.46 & 12.96 & 2.03 & 1.75 \\
\hline AST & 22.21 & 24.08 & 3.29 & 3.17 \\
\hline GST & 23.95 & 28.22 & 4.23 & 4.29 \\
\hline $\mathrm{G}^{\prime} \mathrm{ST}$ & 32.07 & 35.19 & 5.08 & 5.12 \\
\hline
\end{tabular}

${ }^{\mathrm{a}}$ Energies in $\mathrm{kJ} \mathrm{mol}^{-1}$; dipole moments in Debyes $\left(1 \mathrm{D}=3.33564 \times 10^{-30} \mathrm{C} \mathrm{m}\right)$; conformers are depicted in Fig. 1.

${ }^{\mathrm{b}}$ Zero-point energy corrections taken from DFT(B3LYP)/6-311++G(d, p) calculations.

${ }^{\mathrm{c}}$ Total energies with zero-point vibrational energy contribution in parenthesis.

correspond to high energy forms (AAT conformation was found not to be a minimum; in this conformation strong repulsions between the hydroxyl hydrogen atom and both the amino hydrogen atom and the methyl group are operating). The barrier for the $\mathrm{GAT} \rightarrow \mathrm{G}^{\prime}$ AT conversion was predicted by the calculations to be $0.30 \mathrm{~kJ} \mathrm{~mol}^{-1}$, below the zero-point vibrational energy associated with the torsional reaction coordinate at the GAT stationary point of the sarcosine potential energy surface (ca. $2.5 \mathrm{~kJ} \mathrm{~mol}^{-1}$ ). Hence, GAT is better viewed as an excited vibrational state of $\mathrm{G}^{\prime} \mathrm{AT}$, and it has not any practical relevance. The fifth and sixth conformers in the scale of energy (AAC, GAC) show a weak $\mathrm{NH} \cdot \cdots \mathrm{OH}$ hydrogen bond. The estimated energy barrier for the GAC $\rightarrow$ AAC conversion is $9.25 \mathrm{~kJ} \mathrm{~mol}^{-1}$ (see Fig. 2).

The relative energies of the high energy conformers (with a difference of energy to the ground conformational state of more than $8 \mathrm{~kJ} \mathrm{~mol}^{-1}$ ) can also be easily rationalized. Among these forms, $\mathrm{G}^{\prime} \mathrm{SC}$ is the one having the lowest energy. It differs from $\mathrm{G}^{\prime} \mathrm{AC}$ because its methyl group is close to the carbonyl oxygen atom, while in $\mathrm{G}^{\prime} \mathrm{AC}$ the methyl group is close to the sterically more relevant [24-26] oxygen of the hydroxyl group. These two conformers have their carboxylic group in the more favorable cis arrangement but do not possess any kind of stabilizing intramolecular hydrogen bond. The remaining three high energy conformers, as mentioned above, have their carboxylic group in the trans arrangement. The existence of an $\mathrm{NH} \cdots \mathrm{O}=$ intramolecular hydrogen bond in both AST and GST slightly stabilizes these forms relatively to the highest energy $\mathrm{G}^{\prime} \mathrm{ST}$ conformer.

Using the Boltzmann distribution and the predicted $(\mathrm{DFT})^{2}$ relative conformational energies to estimate the populations of the different conformers of sarcosine at room temperature $(298 \mathrm{~K})$, the most stable conformer can be expected to account for $42 \%$ of the total population, G'AT for $24 \%$, GSC for $23 \%$, $\mathrm{AAC} 6 \%$ and GAC for 3\%, with the remaining forms having a joint population of ca. $1 \%$. At $313 \mathrm{~K}$, the temperature used in this study to sublimate the compound within the cryostat during matrix deposition, the populations do not vary more than one unit digit relatively to the room temperature populations. Hence, only the first four conformers are of practical interest and might be expected to be observed experimentally with the techniques used in this study.

The main intramolecular interactions operating in the experimentally relevant conformers, in particular the different types of intramolecular $\mathrm{H}$ bonds $(\mathrm{N}-$ $\mathrm{H} \cdots \mathrm{O}=$ in ASC and $\mathrm{GSC}, \mathrm{N}-\mathrm{H} \cdots \mathrm{O}$ in $\mathrm{AAC}$, and $\mathrm{O}-\mathrm{H} \cdots \mathrm{N}$ in $\mathrm{G}^{\prime} \mathrm{AT}$ ), are clearly reflected in their calculated geometries. In fact, the geometrical parameters of ASC and GSC forms are quite similar,

\footnotetext{
${ }^{2}$ Using MP2 relative energies the populations are (ASC:G'AT: GSC:AAC:GAC) 49\%:22\%:13\%:13\%:3\%.
} 


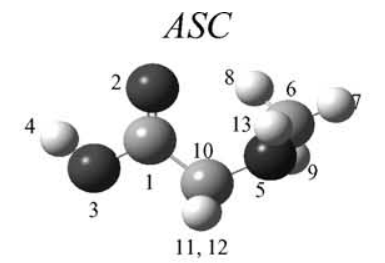

$L p \mathrm{~N}_{5} \mathrm{C}_{10} \mathrm{C}_{1}: 171.5 ; \mathrm{N}_{5} \mathrm{C}_{10} \mathrm{C}_{1}=\mathrm{O}_{2}:-15.4$; $\mathrm{O}_{2} \mathrm{C}_{1} \mathrm{O}_{3} \mathrm{H}_{4}:-1.1$
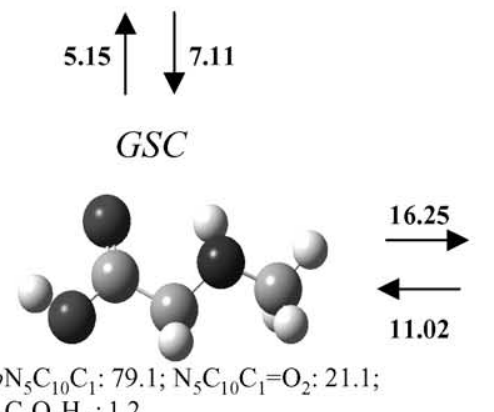

$L p \mathrm{~N}_{5} \mathrm{C}_{10} \mathrm{C}_{1}: 79.1 ; \mathrm{N}_{5} \mathrm{C}_{10} \mathrm{C}_{1}=\mathrm{O}_{2}: 21.1$ $\mathrm{O}_{2} \mathrm{C}_{1} \mathrm{O}_{3} \mathrm{H}_{4}: 1.2$

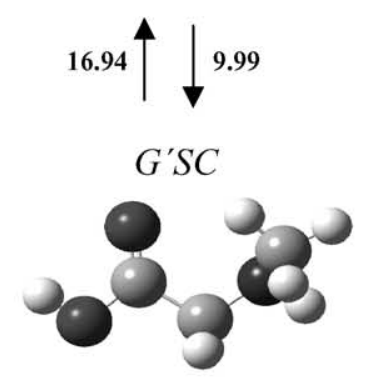

$L p \mathrm{~N}_{5} \mathrm{C}_{10} \mathrm{C}_{1}:-40.9 ; \mathrm{N}_{5} \mathrm{C}_{10} \mathrm{C}_{1}=\mathrm{O}_{2}:-6.5$ $\mathrm{O}_{2} \mathrm{C}_{1} \mathrm{O}_{3} \mathrm{H}_{4}:-0.2$

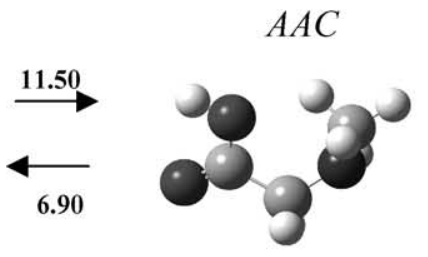

$L p \mathrm{~N}_{4} \mathrm{C}_{13} \mathrm{C}_{1}: 178.2 ; \mathrm{N}_{5} \mathrm{C}_{10} \mathrm{C}_{1}=\mathrm{O}_{2}: 150.1$ $\mathrm{O}_{2} \mathrm{C}_{1} \mathrm{O}_{3} \mathrm{H}_{4}:-0.2$
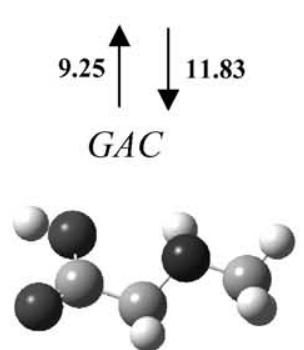

$L p \mathrm{~N}_{5} \mathrm{C}_{10} \mathrm{C}_{1}: 66.2 ; \mathrm{N}_{5} \mathrm{C}_{10} \mathrm{C}_{1}=\mathrm{O}_{2}:-145.2$; $\mathrm{O}_{2} \mathrm{C}_{1} \mathrm{O}_{3} \mathrm{H}_{4}:-1.6$
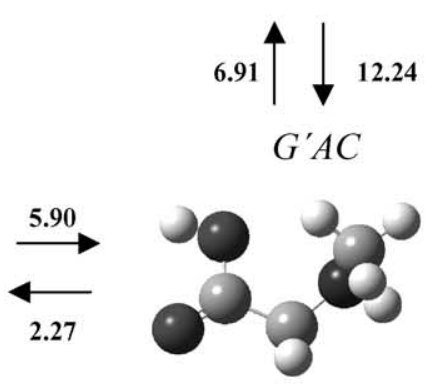

$L p \mathrm{~N}_{5} \mathrm{C}_{10} \mathrm{C}_{1}:-39.8 ; \mathrm{N}_{5} \mathrm{C}_{10} \mathrm{C}_{1}=\mathrm{O}_{2}:-171.4$; $\mathrm{O}_{2} \mathrm{C}_{1} \mathrm{O}_{3} \mathrm{H}_{4}:-0.1$

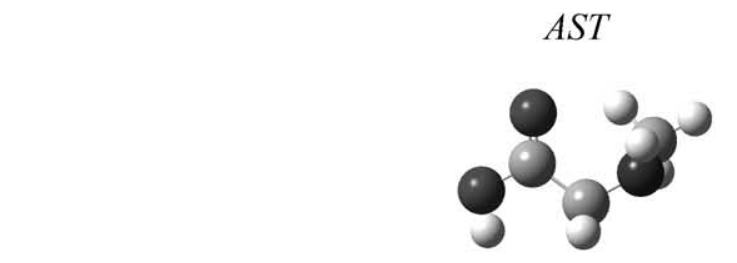

$L p \mathrm{~N}_{5} \mathrm{C}_{10} \mathrm{C}_{1}:-8.6 ; \mathrm{N}_{5} \mathrm{C}_{10} \mathrm{C}_{1}=\mathrm{O}_{2}:-15.7$ $\mathrm{O}_{2} \mathrm{C}_{1} \mathrm{O}_{3} \mathrm{H}_{4}: 178.4$

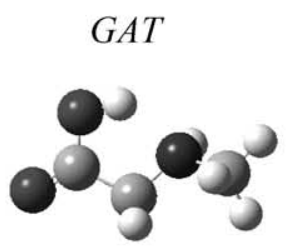

$L p \mathrm{~N}_{5} \mathrm{C}_{10} \mathrm{C}_{1}: 30.0 ; \mathrm{N}_{5} \mathrm{C}_{10} \mathrm{C}_{1}=\mathrm{O}_{2}: 166.7$; $\mathrm{O}_{2} \mathrm{C}_{1} \mathrm{O}_{3} \mathrm{H}_{4}:-178.8$

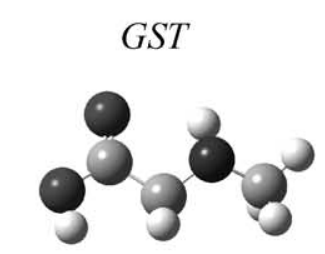

$L p \mathrm{~N}_{5} \mathrm{C}_{10} \mathrm{C}_{1}: 83.0 ; \mathrm{N}_{5} \mathrm{C}_{10} \mathrm{C}_{1}=\mathrm{O}_{2}: 22.2$; $\mathrm{O}_{2} \mathrm{C}_{1} \mathrm{O}_{3} \mathrm{H}_{4}:-176.6$
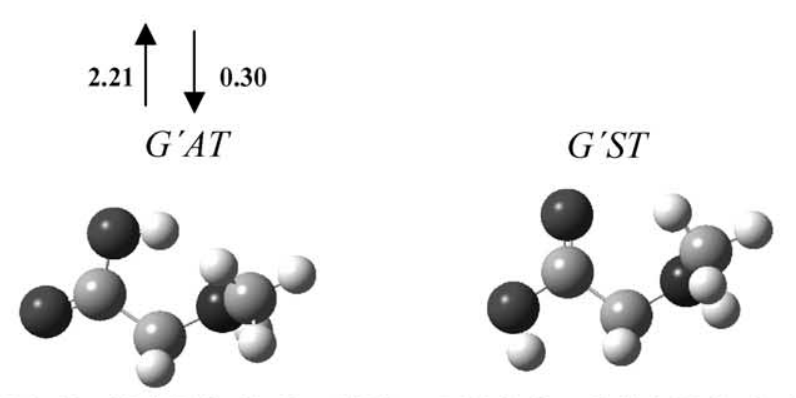

$L p \mathrm{~N}_{5} \mathrm{C}_{10} \mathrm{C}_{1}:-23.4 ; \mathrm{N}_{5} \mathrm{C}_{10} \mathrm{C}_{1}=\mathrm{O}_{2}:-165.8 ; \quad L p \mathrm{~N}_{5} \mathrm{C}_{10} \mathrm{C}_{1}:-42.316 ; \mathrm{N}_{5} \mathrm{C}_{10} \mathrm{C}_{1}=\mathrm{O}_{2}: 2.2 ;$ $\mathrm{O}_{2} \mathrm{C}_{1} \mathrm{O}_{3} \mathrm{H}_{4}: 179.3$

Fig. 1. Conformers of neutral sarcosine with atom numbering scheme and energy barriers $\left(\mathrm{kJ} \mathrm{mol}^{-1}\right)$ for conformational interconversion. For convenience, the values of the most relevant dihedral angles $\left(^{\circ}\right)$ are included. 
Table 2

Supplementary material: optimized geometries for the five most stable conformers of sarcosine

\begin{tabular}{|c|c|c|c|c|c|c|c|c|c|c|}
\hline \multirow[t]{2}{*}{ Parameter } & \multicolumn{2}{|l|}{ ASC } & \multicolumn{2}{|l|}{$\mathrm{G}^{\prime} \mathrm{AT}$} & \multicolumn{2}{|l|}{ GSC } & \multicolumn{2}{|l|}{ GAT } & \multicolumn{2}{|l|}{ AAC } \\
\hline & DFT/B3LYP & MP2 & DFT/B3LYP & MP2 & DFT/B3LYP & MP2 & DFT/B3LYP & MP2 & DFT/B3LYP & MP2 \\
\hline \multicolumn{11}{|l|}{ Bond length (pm) } \\
\hline $\mathrm{C}_{1}=\mathrm{O}_{2}$ & 120.5 & 122.1 & 120.1 & 121.8 & 120.5 & 122.1 & 120.1 & 121.8 & 120.5 & 122.1 \\
\hline $\mathrm{C}_{1}-\mathrm{O}_{3}$ & 135.5 & 136.1 & 134.2 & 135.0 & 135.3 & 135.0 & 134.2 & 135.0 & 135.8 & 136.5 \\
\hline $\mathrm{C}_{1}-\mathrm{C}_{10}$ & 152.8 & 152.0 & 153.7 & 153.0 & 151.2 & 150.8 & 153.5 & 152.8 & 153.0 & 152.2 \\
\hline $\mathrm{O}_{3}-\mathrm{H}_{4}$ & 97.0 & 97.3 & 98.3 & 98.6 & 96.9 & 97.3 & 98.3 & 98.6 & 96.9 & 97.3 \\
\hline $\mathrm{N}_{5}-\mathrm{C}_{6}$ & 146.3 & 146.3 & 146.7 & 146.7 & 145.6 & 145.8 & 146.7 & 146.6 & 146.1 & 146.1 \\
\hline $\mathrm{N}_{5}-\mathrm{H}_{13}$ & 101.4 & 101.5 & 101.2 & 101.4 & 101.4 & 101.5 & 101.4 & 101.7 & 101.3 & 101.4 \\
\hline $\mathrm{N}_{5}-\mathrm{C}_{10}$ & 144.4 & 144.6 & 146.3 & 146.1 & 144.7 & 145.0 & 146.5 & 146.4 & 144.8 & 145.0 \\
\hline $\mathrm{C}_{6}-\mathrm{H}_{7}$ & 109.4 & 109.0 & 109.9 & 109.5 & 109.4 & 109.0 & 109.9 & 109.5 & 109.2 & 108.8 \\
\hline $\mathrm{C}_{6}-\mathrm{H}_{8}$ & 110.0 & 109.6 & 109.3 & 109.0 & 110.4 & 109.9 & 109.2 & 108.8 & 109.4 & 109.0 \\
\hline $\mathrm{C}_{6}-\mathrm{H}_{9}$ & 109.2 & 108.8 & 109.1 & 108.8 & 109.2 & 108.8 & 109.1 & 108.8 & 110.1 & 109.7 \\
\hline $\mathrm{C}_{10}-\mathrm{H}_{11}$ & 109.4 & 109.1 & 109.6 & 109.4 & 110.9 & 110.4 & 109.4 & 109.3 & 109.6 & 109.3 \\
\hline $\mathrm{C}_{10}-\mathrm{H}_{12}$ & 109.7 & 109.3 & 109.4 & 109.2 & 109.4 & 109.1 & 109.5 & 109.3 & 109.2 & 109.0 \\
\hline \multicolumn{11}{|l|}{ Bond angles $\left({ }^{\circ}\right)$} \\
\hline $\mathrm{O}_{2}=\mathrm{C}_{1}-\mathrm{O}_{3}$ & 122.9 & 123.1 & 123.3 & 123.2 & 123.0 & 123.3 & 123.3 & 123.2 & 122.6 & 122.7 \\
\hline $\mathrm{O}_{2}=\mathrm{C}_{1}-\mathrm{C}_{10}$ & 125.5 & 125.3 & 123.2 & 123.3 & 125.3 & 125.0 & 123.1 & 123.1 & 125.1 & 125.8 \\
\hline $\mathrm{O}_{3}-\mathrm{C}_{1}-\mathrm{C}_{10}$ & 111.6 & 111.5 & 113.5 & 113.5 & 111.7 & 111.7 & 113.6 & 113.7 & 112.2 & 111.4 \\
\hline $\mathrm{C}_{1}-\mathrm{O}_{3}-\mathrm{H}_{4}$ & 107.5 & 106.6 & 105.3 & 104.6 & 107.3 & 106.5 & 106.4 & 104.7 & 107.2 & 106.4 \\
\hline $\mathrm{C}_{6}-\mathrm{N}_{5}-\mathrm{C}_{10}$ & 114.5 & 112.8 & 114.6 & 113.0 & 113.9 & 112.2 & 115.2 & 113.6 & 114.6 & 112.8 \\
\hline $\mathrm{C}_{6}-\mathrm{N}_{5}-\mathrm{H}_{13}$ & 110.0 & 109.7 & 110.5 & 110.3 & 111.9 & 111.1 & 109.6 & 109.2 & 110.6 & 110.1 \\
\hline $\mathrm{C}_{13}-\mathrm{N}_{5}-\mathrm{C}_{10}$ & 109.8 & 109.1 & 111.0 & 110.4 & 109.7 & 108.9 & 109.9 & 109.4 & 110.4 & 109.6 \\
\hline $\mathrm{N}_{5}-\mathrm{C}_{6}-\mathrm{H}_{7}$ & 109.2 & 108.5 & 113.1 & 112.8 & 109.8 & 109.1 & 113.5 & 113.2 & 109.1 & 109.0 \\
\hline $\mathrm{N}_{5}-\mathrm{C}_{6}-\mathrm{H}_{8}$ & 114.2 & 113.9 & 109.6 & 108.9 & 113.9 & 113.5 & 109.3 & 108.7 & 109.2 & 108.7 \\
\hline $\mathrm{N}_{5}-\mathrm{C}_{6}-\mathrm{H}_{9}$ & 109.0 & 108.8 & 109.4 & 109.3 & 109.3 & 109.1 & 109.2 & 109.0 & 114.3 & 114.0 \\
\hline $\mathrm{H}_{7}-\mathrm{C}_{6}-\mathrm{H}_{8}$ & 108.5 & 108.8 & 108.1 & 108.4 & 107.7 & 108.1 & 108.3 & 108.6 & 107.6 & 108.2 \\
\hline $\mathrm{H}_{7}-\mathrm{C}_{6}-\mathrm{H}_{9}$ & 107.5 & 108.0 & 108.8 & 109.2 & 107.5 & 108.0 & 108.5 & 108.8 & 108.2 & 108.4 \\
\hline $\mathrm{H}_{8}-\mathrm{C}_{6}-\mathrm{H}_{9}$ & 108.3 & 108.5 & 107.8 & 108.2 & 108.4 & 108.8 & 107.8 & 108.3 & 108.2 & 108.4 \\
\hline $\mathrm{N}_{5}-\mathrm{C}_{10}-\mathrm{H}_{11}$ & 110.0 & 109.6 & 113.8 & 113.9 & 113.8 & 113.8 & 109.0 & 108.4 & 109.2 & 109.2 \\
\hline $\mathrm{N}_{5}-\mathrm{C}_{10}-\mathrm{H}_{12}$ & 110.0 & 110.0 & 109.7 & 109.5 & 110.9 & 110.3 & 114.7 & 114.8 & 110.0 & 109.6 \\
\hline $\mathrm{C}_{1}-\mathrm{C}_{10}-\mathrm{N}_{5}$ & 115.6 & 114.8 & 111.6 & 110.4 & 111.0 & 110.1 & 111.6 & 110.9 & 118.0 & 116.2 \\
\hline $\mathrm{C}_{1}-\mathrm{C}_{10}-\mathrm{H}_{11}$ & 108.6 & 108.6 & 108.0 & 108.0 & 105.8 & 106.2 & 106.2 & 106.5 & 106.0 & 106.9 \\
\hline $\mathrm{C}_{1}-\mathrm{C}_{10}-\mathrm{H}_{12}$ & 106.2 & 106.7 & 106.2 & 106.7 & 109.0 & 109.3 & 108.2 & 108.3 & 106.5 & 106.8 \\
\hline $\mathrm{N}_{5}-\mathrm{C}_{10}-\mathrm{H}_{12}$ & 110.0 & 110.0 & 109.7 & 109.5 & 110.9 & 109.3 & 114.7 & 114.8 & 110.0 & 109.6 \\
\hline $\mathrm{H}_{12}-\mathrm{C}_{10}-\mathrm{H}_{11}$ & 106.0 & 106.8 & 107.2 & 107.9 & 106.1 & 107.0 & 106.8 & 107.4 & 106.6 & 107.8 \\
\hline \multicolumn{11}{|l|}{ Dihedral angles $\left({ }^{\circ}\right)$} \\
\hline $\mathrm{O}_{2}=\mathrm{C}_{1}-\mathrm{O}_{3}-\mathrm{H}_{4}$ & -1.1 & -1.4 & 179.2 & 178.9 & 1.2 & 1.3 & -178.8 & -178.4 & -0.2 & -0.1 \\
\hline $\mathrm{N}_{5}-\mathrm{C}_{10}-\mathrm{C}_{1}=\mathrm{O}_{2}$ & -15.4 & -19.0 & -165.8 & -162.2 & 21.1 & 26.2 & 166.7 & 164.1 & 150.1 & 141.7 \\
\hline $\mathrm{O}_{2}=\mathrm{C}_{1}-\mathrm{C}_{10}-\mathrm{H}_{11}$ & -139.5 & -142.0 & -40.0 & -37.1 & -102.7 & -97.5 & -74.7 & -78.1 & -87.3 & -96.1 \\
\hline $\mathrm{O}_{2}=\mathrm{C}_{1}-\mathrm{C}_{10}-\mathrm{H}_{12}$ & 106.9 & 103.1 & 74.6 & 78.8 & 143.6 & 147.5 & 39.7 & 37.3 & 26.0 & 19.1 \\
\hline $\mathrm{C}_{10}-\mathrm{N}_{5}-\mathrm{C}_{6}-\mathrm{H}_{7}$ & -63.4 & -64.3 & 58.7 & 58.5 & -64.8 & -64.6 & 58.0 & 56.2 & 179.6 & 179.7 \\
\hline $\mathrm{C}_{10}-\mathrm{N}_{5}-\mathrm{C}_{6}-\mathrm{H}_{8}$ & 58.2 & 57.2 & -61.9 & -61.8 & 56.0 & 56.0 & -63.1 & -64.6 & -62.1 & -62.7 \\
\hline $\mathrm{C}_{10}-\mathrm{N}_{5}-\mathrm{C}_{6}-\mathrm{H}_{9}$ & 179.4 & 178.4 & -179.8 & -179.8 & 177.4 & 177.6 & 179.2 & 177.5 & 59.2 & 58.4 \\
\hline $\mathrm{H}_{13}-\mathrm{N}_{5}-\mathrm{C}_{10}-\mathrm{H}_{11}$ & 177.1 & 176.8 & 97.2 & 91.0 & 81.3 & 76.4 & 155.2 & 157.9 & -59.9 & -58.5 \\
\hline $\mathrm{H}_{13}-\mathrm{N}_{5}-\mathrm{C}_{10}-\mathrm{H}_{12}$ & -66.6 & -66.0 & -22.9 & -30.0 & -159.2 & -163.4 & 35.6 & 37.8 & -176.6 & -176.3 \\
\hline $\mathrm{C}_{6}-\mathrm{N}_{5}-\mathrm{C}_{10}-\mathrm{C}_{1}$ & -70.7 & -68.0 & 93.5 & 88.7 & -164.0 & -166.1 & 147.8 & 152.3 & -64.7 & -60.5 \\
\hline $\mathrm{H}_{13}-\mathrm{N}_{5}-\mathrm{C}_{10}-\mathrm{C}_{1}$ & 53.7 & 54.2 & -140.3 & -147.3 & -37.8 & -42.7 & -87.8 & -85.4 & 61.1 & 62.5 \\
\hline \multicolumn{11}{|c|}{ Rotational constants $(\mathrm{MHz})$} \\
\hline A & 7114.4 & 6897.8 & 7207.5 & 6941.8 & 9421.5 & 9239.6 & 8965.3 & 8946.4 & 6514.3 & 6227.7 \\
\hline B & 2263.3 & 2319.5 & 2260.1 & 2325.4 & 1929.8 & 1945.5 & 2008.3 & 2015.1 & 2340.0 & 2409.3 \\
\hline $\mathrm{C}$ & 2010.9 & 2066.5 & 2023.4 & 2093.7 & 1650.6 & 1660.4 & 1728.5 & 1728.2 & 2134.3 & 2239.3 \\
\hline
\end{tabular}

\footnotetext{
${ }^{\mathrm{a}}$ See Fig. 1 for atom numbering.
} 

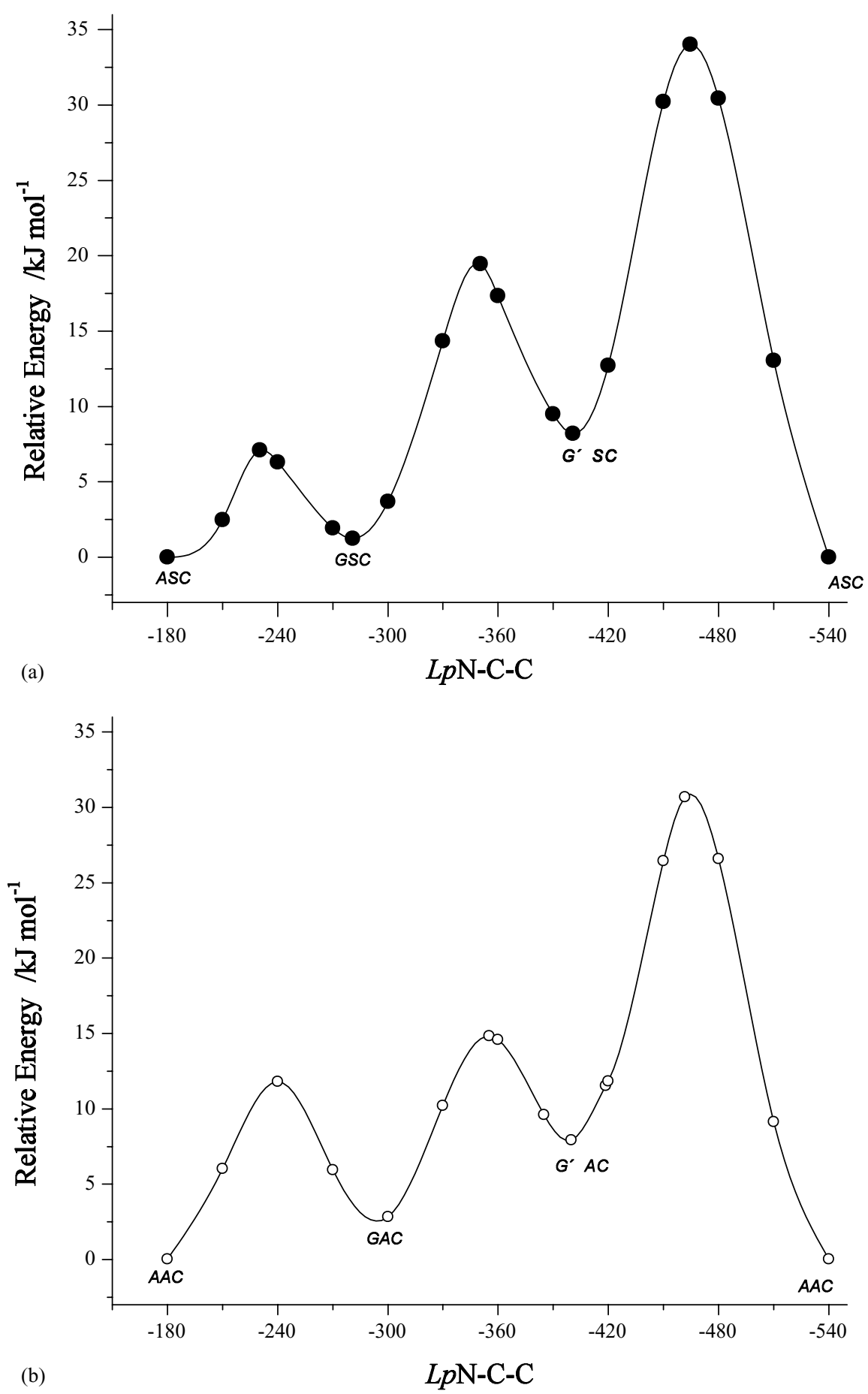

Fig. 2. DFT(B3LYP)/6-311++G(d, p) calculated potential energy profile for internal rotation around the $\mathrm{N}_{5}-\mathrm{C}_{10}$ bond. (a) ASC $\leftrightarrow$ GSC $\leftrightarrow \mathrm{G}^{\prime} \mathrm{SC}$ interconversion path (๑); (b) AAC $\leftrightarrow \mathrm{GAC} \leftrightarrow \mathrm{G}^{\prime} \mathrm{AC}$ interconversion path (O). 
except for the conformation defining dihedral angles and $\mathrm{C}-\mathrm{C}-\mathrm{N}$ angle, which is $4^{\circ}$ larger in ASC as a result of the repulsion between the positively charged methylenic and methyl hydrogen atoms that are close to each other for this conformer. This angle is still larger in AAC $\left(118.0^{\circ}\right.$ versus $111.0^{\circ}$ in GSC) due to the presence in this conformer of the stronger steric repulsion between the methyl group and the lone electron pairs of the hydroxyl oxygen atom, which is well known to be sterically considerably more relevant than the carbonyl oxygen. On the other hand, the geometric parameters of the $\mathrm{G}^{\prime} \mathrm{AT}$ conformer, which is among the conformers of sarcosine now under consideration that differing more in structural terms, are significantly different from those predicted for the remaining forms. Besides the $\mathrm{O}-\mathrm{H}$ bond length, that is longer in this case due to the involvement of this group in the intramolecular $\mathrm{H}$-bond, in $\mathrm{G}^{\prime} \mathrm{AT}$ the $\mathrm{C}-\mathrm{C}$ and $\mathrm{N}-\mathrm{C}$ bond lengths as well as the $\mathrm{O}-\mathrm{C}-\mathrm{C}$ and $\mathrm{C}-\mathrm{N}-\mathrm{C}$ angles increase their values in order to accommodate the H-O-C-C-N $\mathrm{N}_{\mathrm{LP}}$ fivemembered ring that characterizes structurally this conformer. G'AT does also exhibit a larger charge separation within the molecule, that is well reflected in its larger dipole moment (see Table 1). This charge separation may also be partially responsible for the above mentioned general increase calculated for the bond lengths and valence angles within the $\mathrm{H}-\mathrm{O}-\mathrm{C}-$ $\mathrm{C}-\mathrm{N}_{\mathrm{Lp}}$ fragment.

Having located all minima on the sarcosine potential energy surface, an effort was made to calculate the potential energy profile for all possible interconversions among the cis carboxylate conformers. These interconversions correspond essentially to two internal rotations: one around the $\mathrm{C}-\mathrm{N}$ central bond, and the other around the $\mathrm{C}-\mathrm{C}$ bond. The results are shown in Figs. 2 and 3. There are several energy barriers that are predicted by the calculations to be relatively low. For example, among the interconversions involving the 4 conformers with practical relevance, the GSC $\rightarrow$ ASC barrier is ca. $5 \mathrm{~kJ} \mathrm{~mol}^{-1}$ and the barrier corresponding to the lowest energy path for the AAC $\rightarrow$ ASC conversion is ca. $7 \mathrm{~kJ} \mathrm{~mol}^{-1}$, respectively. Thus, depending on the experimental conditions used to deposit the matrices (in particular the temperature of the cold substrate) we may observe conformational cooling to take place during matrix deposition: the higher the temperature of the substrate, the more important the conformational cooling [27].

\subsection{Vibrational spectra}

The infrared spectrum of sarcosine isolated in an argon matrix at $9 \mathrm{~K}$ is presented in Fig. 4. Figs. 5-8 show the most important spectral regions of the IR spectra of the matrix subjected to annealing within the temperature range 9-20 K. In these figures, the calculated (DFT) spectra for the four predicted most stable relevant conformers of sarcosine (GAT was excluded by the reasons above discussed) are also plotted, using as weighting factors for intensities the estimated relative populations resulting from the DFT calculations. When MP2 predicted relative populations are used, the agreement between the experimental and calculated spectra is slightly worse, pointing to a better description of the potential energy surface of sarcosine by the DFT calculations. Definition of the internal coordinates used in the normal coordinates analysis is presented in Table 3. Assignments are presented in Tables 4-7.

In spite of the practical difficulty in our set up to determine the matrix to solute ratios, the concentration of the matrices were kept low enough to guarantee that immediately after deposition no aggregates were present. Mark bands due to aggregates were determined by analysis of spectra of more concentrated matrices (Fig. 9). The most prominent of these bands appear in the spectra of the concentrated matrices at $3160 \mathrm{~cm}^{-1}$ $(v \mathrm{OH}), 1720 \mathrm{~cm}^{-1}(v \mathrm{C}=\mathrm{O}), 1248 \mathrm{~cm}^{-1}(v \mathrm{C}-\mathrm{O} / \delta \mathrm{COH})$, $1182 \mathrm{~cm}^{-1}(\nu \mathrm{C}-\mathrm{N})$ and $549 \mathrm{~cm}^{-1}(\gamma \mathrm{C}=\mathrm{O})$. These bands were observed to appear at wavenumbers that agree very well with those predicted by DFT/6$311++\mathrm{G}(\mathrm{d}, \mathrm{p})$ calculations for the carboxylic acid like dimer of sarcosine where the two monomeric units assume the most stable ASC conformation (see Fig. 9). The calculated (scaled) wavenumbers for the intense mark bands of the dimer above mentioned are (3161, $1716,1245,1178$ and $\left.547 \mathrm{~cm}^{-1}\right) .^{3}$

As expected, the spectrum of matrix-isolated sarcosine is dominated by the bands due to the most stable conformer (ASC), which in most of the cases

\footnotetext{
${ }^{3}$ The dimerization energy, calculated as the difference between the energy of the dimer and twice the energy of the monomer (ASC), amounts to $-59.4 \mathrm{~kJ} \mathrm{~mol}^{-1}$.
} 

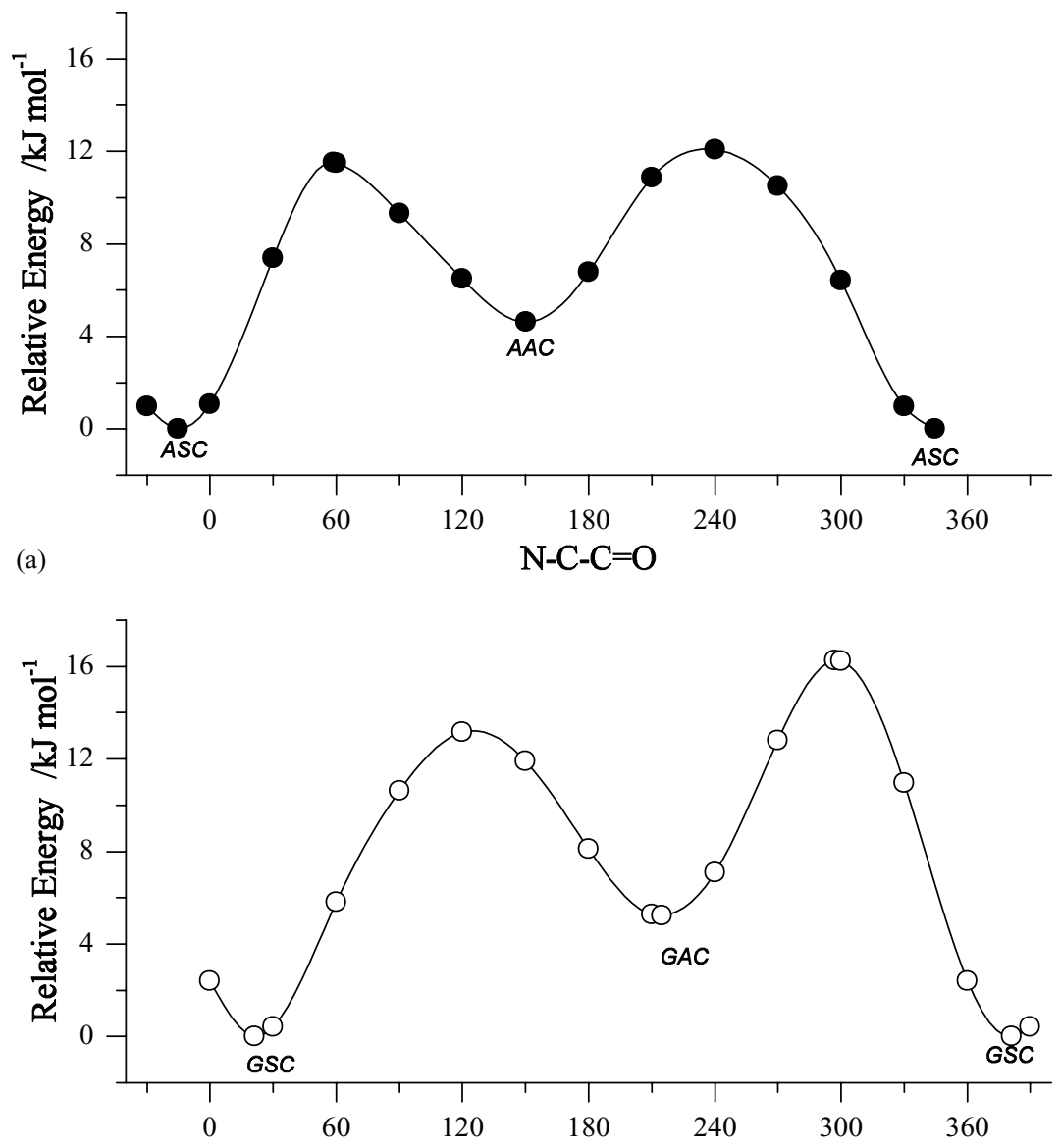

(b)

$\mathrm{N}-\mathrm{C}-\mathrm{C}=\mathrm{O}$

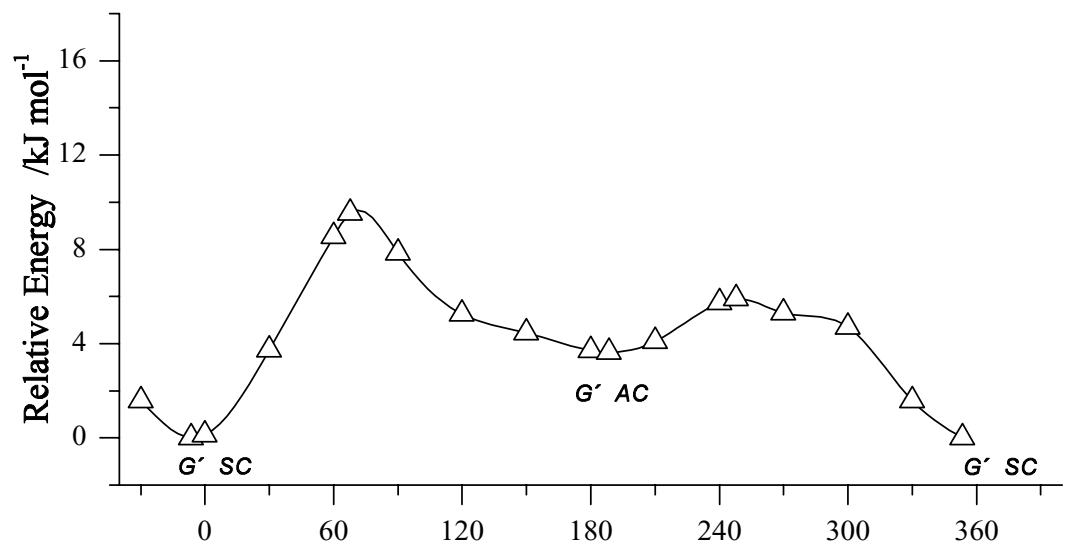

(c)

$\mathrm{N}-\mathrm{C}-\mathrm{C}=\mathrm{O}$

Fig. 3. DFT(B3LYP)/6-311++G(d, p) calculated potential energy profile for internal rotation around the $\mathrm{C}_{1}-\mathrm{C}_{2}$ bond. (a) ASC $\leftrightarrow$ AAC (b) GSC $\leftrightarrow$ GAC $(\bigcirc)$ and (c) $\mathrm{G}^{\prime} \mathrm{SC} \leftrightarrow \mathrm{G}^{\prime} \mathrm{AC}(\triangle)$ interconversion paths. 
Table 3

Supplementary material: definition of internal coordinates used in the normal coordinate analysis

\begin{tabular}{|c|c|c|}
\hline & Definition & Approximate description \\
\hline $\mathrm{S}_{1}$ & $v \mathrm{C}_{1}-\mathrm{O}_{2}$ & $\nu \mathrm{C}=\mathrm{O}$ \\
\hline $\mathrm{S}_{2}$ & $v \mathrm{C}_{1}-\mathrm{O}_{3}$ & $\nu \mathrm{C}-\mathrm{O}$ \\
\hline $\mathrm{S}_{3}$ & $v \mathrm{O}_{3}-\mathrm{H}_{4}$ & $v \mathrm{O}-\mathrm{H}$ \\
\hline $\mathrm{S}_{4}$ & $v \mathrm{C}_{1}-\mathrm{C}_{10}$ & $\nu \mathrm{C}-\mathrm{C}$ \\
\hline $\mathrm{S}_{5}$ & $v\left(\mathrm{C}_{10}-\mathrm{H}_{11}\right)+v\left(\mathrm{C}_{10}-\mathrm{H}_{12}\right)$ & $v \mathrm{CH}_{2} \mathrm{~s}$ \\
\hline $\mathrm{S}_{6}$ & $v\left(\mathrm{C}_{10}-\mathrm{H}_{11}\right)-v\left(\mathrm{C}_{10}-\mathrm{H}_{12}\right)$ & $v \mathrm{CH}_{2}$ as \\
\hline $\mathrm{S}_{7}$ & $v \mathrm{C}_{10}-\mathrm{N}_{5}$ & $v \mathrm{C}-\mathrm{N}$ \\
\hline $\mathrm{S}_{8}$ & $v \mathrm{~N}_{5}-\mathrm{C}_{6}$ & $v \mathrm{~N}-\mathrm{C}$ \\
\hline $\mathrm{S}_{9}$ & $v \mathrm{~N}_{5}-\mathrm{H}_{13}$ & $v \mathrm{~N}-\mathrm{H}$ \\
\hline $\mathrm{S}_{10}$ & $v\left(\mathrm{C}_{6}-\mathrm{H}_{7}\right)+v\left(\mathrm{C}_{6}-\mathrm{H}_{8}\right)+v\left(\mathrm{C}_{6}-\mathrm{H}_{9}\right)$ & $v \mathrm{CH}_{3} \mathrm{~s}$ \\
\hline $\mathrm{S}_{11}$ & $2 v\left(\mathrm{C}_{6}-\mathrm{H}_{7}\right)-v\left(\mathrm{C}_{6}-\mathrm{H}_{8}\right)-v\left(\mathrm{C}_{6}-\mathrm{H}_{9}\right)$ & $\nu \mathrm{CH}_{3}$ as $^{\prime}$ \\
\hline $\mathrm{S}_{12}$ & $v\left(\mathrm{C}_{6}-\mathrm{H}_{8}\right)-v\left(\mathrm{C}_{6}-\mathrm{H}_{9}\right)$ & $\nu \mathrm{CH}_{3} \mathrm{as}^{\prime \prime}$ \\
\hline $\mathrm{S}_{13}$ & $\delta \mathrm{C}_{1}-\mathrm{O}_{3}-\mathrm{H}_{4}$ & $\delta \mathrm{COH}$ \\
\hline $\mathrm{S}_{14}$ & $2 \delta\left(\mathrm{O}_{2}=\mathrm{C}_{1}-\mathrm{O}_{3}\right)-\delta\left(\mathrm{C}_{10}-\mathrm{C}_{1}=\mathrm{O}_{2}\right)-\delta\left(\mathrm{C}_{10}-\mathrm{C}_{1}-\mathrm{O}_{3}\right)$ & $\delta \mathrm{OCO}$ \\
\hline $\mathrm{S}_{15}$ & $\delta\left(\mathrm{C}_{10}-\mathrm{C}_{1}=\mathrm{O}_{2}\right)-\delta\left(\mathrm{C}_{10}-\mathrm{C}_{1}-\mathrm{O}_{3}\right)$ & $\delta \mathrm{C}-\mathrm{C}=\mathrm{O}$ \\
\hline $\mathrm{S}_{16}$ & $\begin{array}{l}5\left(\mathrm{H}_{11}-\mathrm{C}_{10}-\mathrm{H}_{12}\right)-\delta\left(\mathrm{H}_{11}-\mathrm{C}_{10}-\mathrm{C}_{1}\right)-\delta\left(\mathrm{H}_{12}-\mathrm{C}_{10}-\mathrm{C}_{1}\right)-\delta\left(\mathrm{H}_{11}-\mathrm{C}_{10}-\mathrm{N}_{5}\right)-\delta\left(\mathrm{H}_{12}-\mathrm{C}_{10}-\mathrm{N}_{5}\right) \\
-\delta\left(\mathrm{N}_{5}-\mathrm{C}_{10}-\mathrm{C}_{1}\right)\end{array}$ & $\delta \mathrm{CH}_{2}$ \\
\hline $\mathrm{S}_{17}$ & $-\delta\left(\mathrm{H}_{11}-\mathrm{C}_{10}-\mathrm{C}_{1}\right)-\delta\left(\mathrm{H}_{12}-\mathrm{C}_{10}-\mathrm{C}_{1}\right)-\delta\left(\mathrm{H}_{11}-\mathrm{C}_{10}-\mathrm{N}_{5}\right)-\delta\left(\mathrm{H}_{12}-\mathrm{C}_{10}-\mathrm{N}_{5}\right)+4 \delta\left(\mathrm{N}_{5}-\mathrm{C}_{10}-\mathrm{C}_{1}\right)$ & $\delta \mathrm{NCC}$ \\
\hline $\mathrm{S}_{18}$ & $\delta\left(\mathrm{H}_{11}-\mathrm{C}_{10}-\mathrm{C}_{1}\right)+\delta\left(\mathrm{H}_{12}-\mathrm{C}_{10}-\mathrm{C}_{1}\right)-\delta\left(\mathrm{H}_{11}-\mathrm{C}_{10}-\mathrm{N}_{5}\right)-\delta\left(\mathrm{H}_{12}-\mathrm{C}_{10}-\mathrm{N}_{5}\right)$ & $\omega \mathrm{CH}_{2}$ \\
\hline $\mathrm{S}_{19}$ & $\delta\left(\mathrm{H}_{11}-\mathrm{C}_{10}-\mathrm{C}_{1}\right)-\delta\left(\mathrm{H}_{12}-\mathrm{C}_{10}-\mathrm{C}_{1}\right)-\delta\left(\mathrm{H}_{11}-\mathrm{C}_{10}-\mathrm{N}_{5}\right)+\delta\left(\mathrm{H}_{12}-\mathrm{C}_{10}-\mathrm{N}_{5}\right)$ & $\mathrm{twCH}_{2}$ \\
\hline $\mathrm{S}_{20}$ & $\delta\left(\mathrm{H}_{11}-\mathrm{C}_{10}-\mathrm{C}_{1}\right)-\delta\left(\mathrm{H}_{12}-\mathrm{C}_{10}-\mathrm{C}_{1}\right)+\delta\left(\mathrm{H}_{11}-\mathrm{C}_{10}-\mathrm{N}_{5}\right)-\delta\left(\mathrm{H}_{12}-\mathrm{C}_{10}-\mathrm{N}_{5}\right)$ & $\gamma \mathrm{CH}_{2}$ \\
\hline $\mathrm{S}_{21}$ & $2 \delta\left(\mathrm{C}_{6}-\mathrm{N}_{5}-\mathrm{C}_{10}\right)-\delta\left(\mathrm{C}_{6}-\mathrm{N}_{5}-\mathrm{H}_{13}\right)-\delta\left(\mathrm{C}_{13}-\mathrm{N}_{5}-\mathrm{H}_{10}\right)$ & $\delta \mathrm{CNC}$ \\
\hline $\mathrm{S}_{22}$ & $\delta\left(\mathrm{C}_{6}-\mathrm{N}_{5}-\mathrm{H}_{13}\right)-\delta\left(\mathrm{C}_{6}-\mathrm{N}_{5}-\mathrm{C}_{10}\right)$ & $\delta \mathrm{NH}$ \\
\hline $\mathrm{S}_{23}$ & $\delta\left(\mathrm{H}_{8} \mathrm{C}_{6} \mathrm{H}_{9}\right)+\delta\left(\mathrm{H}_{9} \mathrm{C}_{6} \mathrm{H}_{7}\right)+\delta\left(\mathrm{H}_{8} \mathrm{C}_{6} \mathrm{H}_{7}\right)-\delta\left(\mathrm{H}_{8} \mathrm{C}_{6} \mathrm{~N}_{5}\right)-\delta\left(\mathrm{H}_{9} \mathrm{C}_{6} \mathrm{~N}_{5}\right)-\delta\left(\mathrm{H}_{7} \mathrm{C}_{6} \mathrm{~N}_{5}\right)$ & $\delta \mathrm{CH}_{3} \mathrm{~s}$ \\
\hline $\mathrm{S}_{24}$ & $2 \delta\left(\mathrm{H}_{8} \mathrm{C}_{6} \mathrm{H}_{9}\right)-\delta\left(\mathrm{H}_{9} \mathrm{C}_{6} \mathrm{H}_{7}\right)-\delta\left(\mathrm{H}_{8} \mathrm{C}_{6} \mathrm{H}_{7}\right)$ & $\delta \mathrm{CH}_{3}$ as $^{\prime}$ \\
\hline $\mathrm{S}_{25}$ & $\delta\left(\mathrm{H}_{9} \mathrm{C}_{6} \mathrm{H}_{7}\right)-\delta\left(\mathrm{H}_{8} \mathrm{C}_{6} \mathrm{H}_{7}\right)$ & $\delta \mathrm{CH}_{3} \mathrm{as}^{\prime \prime}$ \\
\hline $\mathrm{S}_{26}$ & $2 \delta\left(\mathrm{H}_{7} \mathrm{C}_{6} \mathrm{~N}_{5}\right)-\delta\left(\mathrm{H}_{9} \mathrm{C}_{6} \mathrm{~N}_{5}\right)-\delta\left(\mathrm{H}_{8} \mathrm{C}_{6} \mathrm{~N}_{5}\right)$ & $\gamma \mathrm{CH}_{3}^{\prime}$ \\
\hline $\mathrm{S}_{27}$ & $\delta\left(\mathrm{H}_{9} \mathrm{C}_{6} \mathrm{~N}_{5}\right)-\delta\left(\mathrm{H}_{8} \mathrm{C}_{6} \mathrm{~N}_{5}\right)$ & $\gamma \mathrm{CH}_{3}^{\prime \prime}$ \\
\hline $\mathrm{S}_{28}$ & $\tau \mathrm{O}_{2}=\mathrm{C}_{1}-\mathrm{O}_{3}-\mathrm{H}_{4}$ & $\tau \mathrm{C}-\mathrm{O}$ \\
\hline $\mathrm{S}_{29}$ & $\tau \mathrm{N}_{5}-\mathrm{C}_{10}-\mathrm{C}_{1}=\mathrm{O}_{2}$ & $\tau \mathrm{C}-\mathrm{C}$ \\
\hline $\mathrm{S}_{30}$ & $\tau \mathrm{C}_{1}-\mathrm{C}_{10}-\mathrm{N}_{5}-\mathrm{C}_{6}$ & $\tau \mathrm{C}-\mathrm{N}$ \\
\hline $\mathrm{S}_{31}$ & $\tau \mathrm{C}_{10}-\mathrm{N}_{5}-\mathrm{C}_{6}-\mathrm{H}_{7}$ & $\tau \mathrm{NC}$ \\
\hline $\mathrm{S}_{32}$ & $\mathrm{O}_{2}$ out of plane $\mathrm{C}_{10}-\mathrm{C}_{1}-\mathrm{O}_{3}$ & $\gamma \mathrm{C}=\mathrm{O}$ \\
\hline $\mathrm{S}_{33}$ & Inversion & Inversion \\
\hline
\end{tabular}

$\nu$, bond stretching; $\delta$, bending; $\gamma$, rocking; $\omega$, wagging; tw, twisting; $\tau$, torsion; s, symmetric; as, asymmetric.

appear splitted due to matrix-site effects. The most intense bands of this conformer are predicted to occur at $1772 \mathrm{~cm}^{-1}(\nu \mathrm{C}=\mathrm{O}), 1132 \mathrm{~cm}^{-1}\left(\gamma \mathrm{CH}_{3}{ }^{\prime}\right), 1104 \mathrm{~cm}^{-1}$ $(\nu \mathrm{C}-\mathrm{O}), 724 \mathrm{~cm}^{-1}$ (amine inversion) and $641 \mathrm{~cm}^{-1}$ $(\tau \mathrm{C}-\mathrm{O})$ and were observed at nearly the same wavenumbers (see Table 4). The assignment of all vibrations of ASC (except those predicted to occur in the non-investigated spectral region below $400 \mathrm{~cm}^{-1}$ and the very low intensity $\mathrm{N}-\mathrm{H}$ stretching band) could be made with leisure, being facilitated by the fact that, upon annealing of the matrix to higher temperatures, the intensity of the bands due to this conformer increases, while those due to the remaining experimentally observed conformers reduce. This is clearly shown in Figs. 5-8, which present selected (most intense) regions of the spectra of matrix-isolated sarcosine obtained immediately after deposition and after annealing to $20 \mathrm{~K}$, and compare these spectra with the DFT predicted data.

The three vibrations of ASC expected to be observed in the $1080-1160 \mathrm{~cm}^{-1}$ region (Fig. 5) are assigned to the strong bands at $1109 \mathrm{~cm}^{-1}(v \mathrm{C}-\mathrm{O})$ and $1138 \mathrm{~cm}^{-1} / 1141 \mathrm{~cm}^{-1}\left(\gamma \mathrm{CH}_{3}{ }^{\prime}\right.$; site splitted $)$, and to the medium intensity doublet at $1135 \mathrm{~cm}^{-1} / 1132 \mathrm{~cm}^{-1}$ $(v \mathrm{~N}-\mathrm{C}$; site splitted). All these bands increase of intensity upon annealing of the matrix. Conformer GSC 


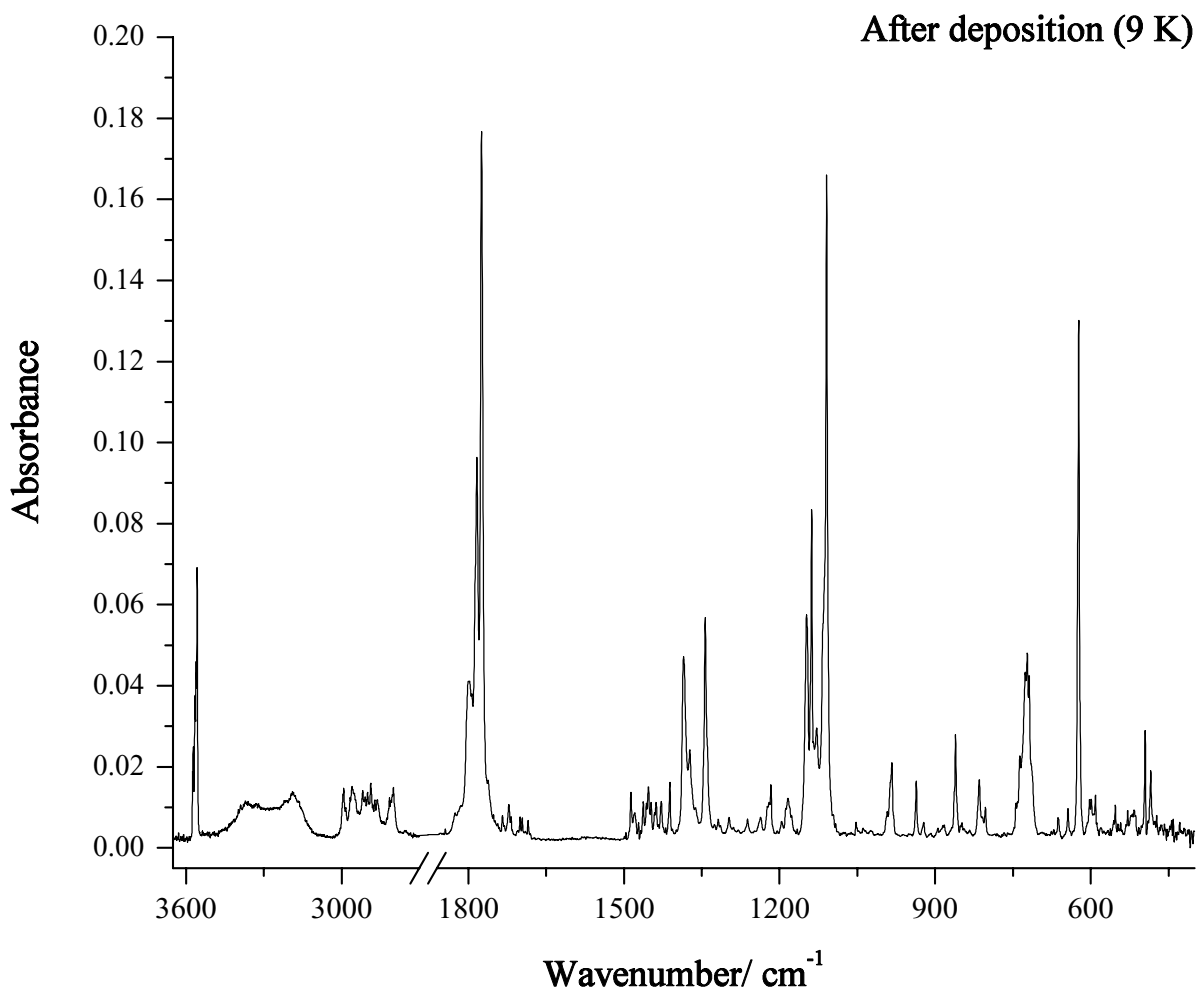

Fig. 4. Infrared spectra of sarcosine trapped in an argon matrix. Spectra obtained immediately after deposition at $9 \mathrm{~K}$. Temperature of sublimation $=40^{\circ} \mathrm{C}$.

gives the largest contribution to the intensity of the site splitted band at $1146 \mathrm{~cm}^{-1} / 1148 \mathrm{~cm}^{-1}(v \mathrm{~N}-\mathrm{C})$ and shoulder at $1114 \mathrm{~cm}^{-1} / 1117 \mathrm{~cm}^{-1}(\nu \mathrm{C}-\mathrm{O})$, and also a minor contribution to the intensity of the band at $1128 \mathrm{~cm}^{-1}$, which reduce of intensity upon annealing. Taking into account their expected relative populations in the matrix, the remaining two conformers $\left(\mathrm{G}^{\prime} \mathrm{AT}\right.$ and $\mathrm{AAC}$ ) were not expected to give rise to strong bands in this spectral region: $\mathrm{G}^{\prime} \mathrm{AT}$ vibrations were assigned as contributors to the bands at $1128 \mathrm{~cm}^{-1}$ $\left(\gamma \mathrm{CH}_{3}{ }^{\prime}\right), 1146 \mathrm{~cm}^{-1} / 1148 \mathrm{~cm}^{-1}\left(\gamma \mathrm{CH}_{3}^{\prime \prime}\right.$; minor contributor) and shoulder at ca. $1106 \mathrm{~cm}^{-1}(\nu \mathrm{C}-\mathrm{N})$; AAT vibrations were ascribed to the small band at $1101 \mathrm{~cm}^{-1}(v \mathrm{C}-\mathrm{O})$ and shoulder at $1150 \mathrm{~cm}^{-1}$, and as minor contributors to the intensity of the band at $1128 \mathrm{~cm}^{-1}\left(\gamma \mathrm{CH}_{3}{ }^{\prime}\right)$. As it can be observed in Fig. 5, in this region the calculated spectra fit nicely the experimental data.

In the 1330-1400 $\mathrm{cm}^{-1}$ spectral region (Fig. 6), one very intense band due to $\mathrm{G}^{\prime} \mathrm{AT}$ is expected to occur.
This band should correspond to the $\delta \mathrm{COH}$ bending mode, which in the remaining conformers is predicted to occur at considerably lower wavenumbers. In the same spectral region, only two additional bands were predicted to occur, corresponding to the $\omega \mathrm{CH}_{2}$ modes of ASC and GSC. In the experimental spectra, besides the lower intensity bands near 1375 and $1360 \mathrm{~cm}^{-1}$ (the last increasing of intensity upon annealing), which can be easily ascribed to the wagging modes of GSC and ASC conformers, two strong bands (both exhibiting shoulders due to matrix-site splitting) are observed at ca. 1385 and $1345 \mathrm{~cm}^{-1}$. These two strong bands are ascribed to the $\delta \mathrm{COH}$ bending mode of $\mathrm{G}^{\prime} \mathrm{AT}$ in Fermi resonance with the $\tau \mathrm{C}-\mathrm{O}+$ $\gamma \mathrm{C}=\mathrm{O}$ combination mode, whose fundamentals are observed at 815 and $553 \mathrm{~cm}^{-1}$, respectively (see Table 5). It is interesting to note that a similar phenomenon was previously reported to occur in matrixisolated DMG, for a conformer structurally similar to $\mathrm{G}^{\prime} \mathrm{AT}$ [11]. 


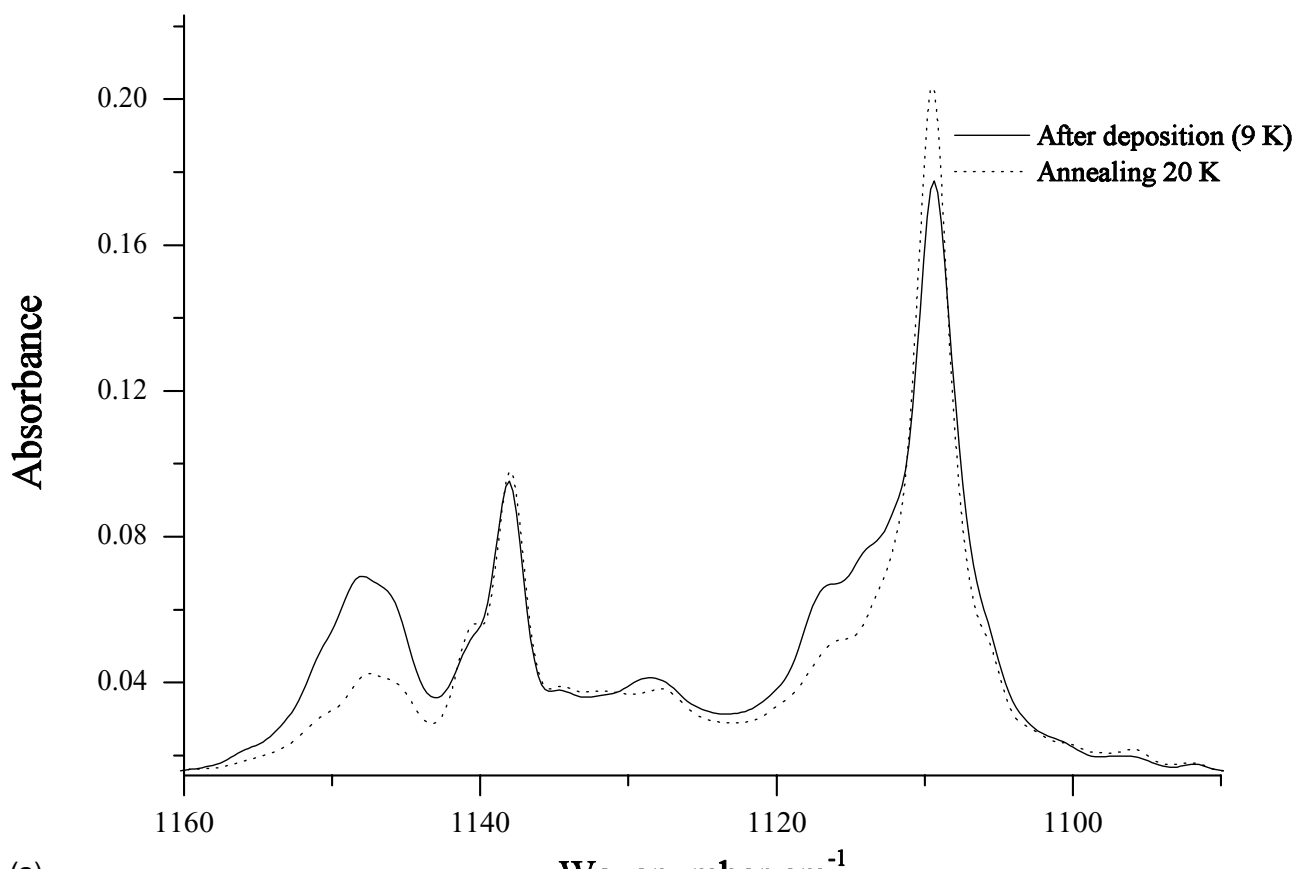

(a)

Wavenumber $\mathrm{cm}^{-1}$

ב⿱艹

(b)

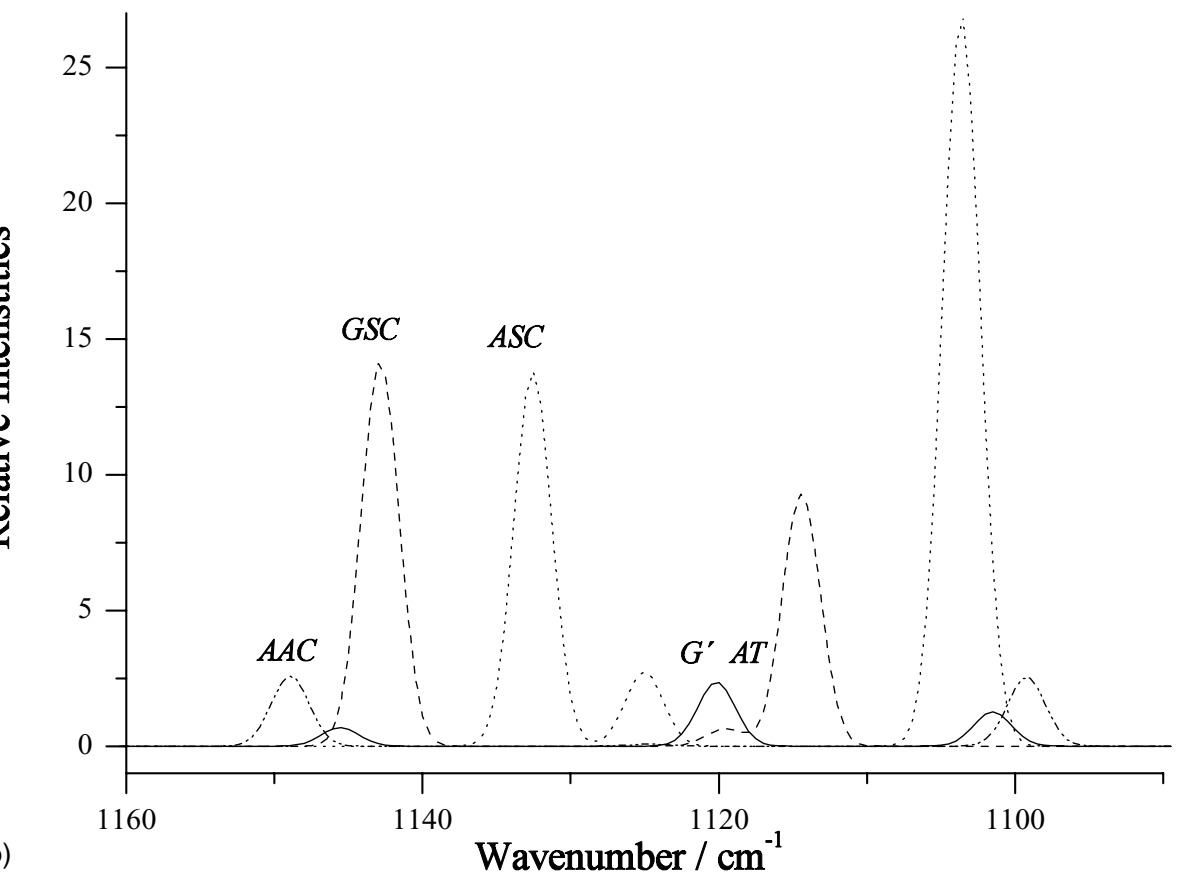

Fig. 5. Comparison of (a) the experimental spectrum (1080-1160 $\mathrm{cm}^{-1}$ region) of matrix-isolated sarcosine (in argon), obtained immediately after deposition at $9 \mathrm{~K}(-)$ and after annealing of the matrix to $20 \mathrm{~K}(---)$, with (b) the DFT(B3LYP)/6-311++G(d, p) calculated spectra for the experimentally observed conformers of sarcosine. Calculated integral intensities were weighted by the relative populations of the different conformers at the sublimation temperature, estimated from the DFT calculated energies. 

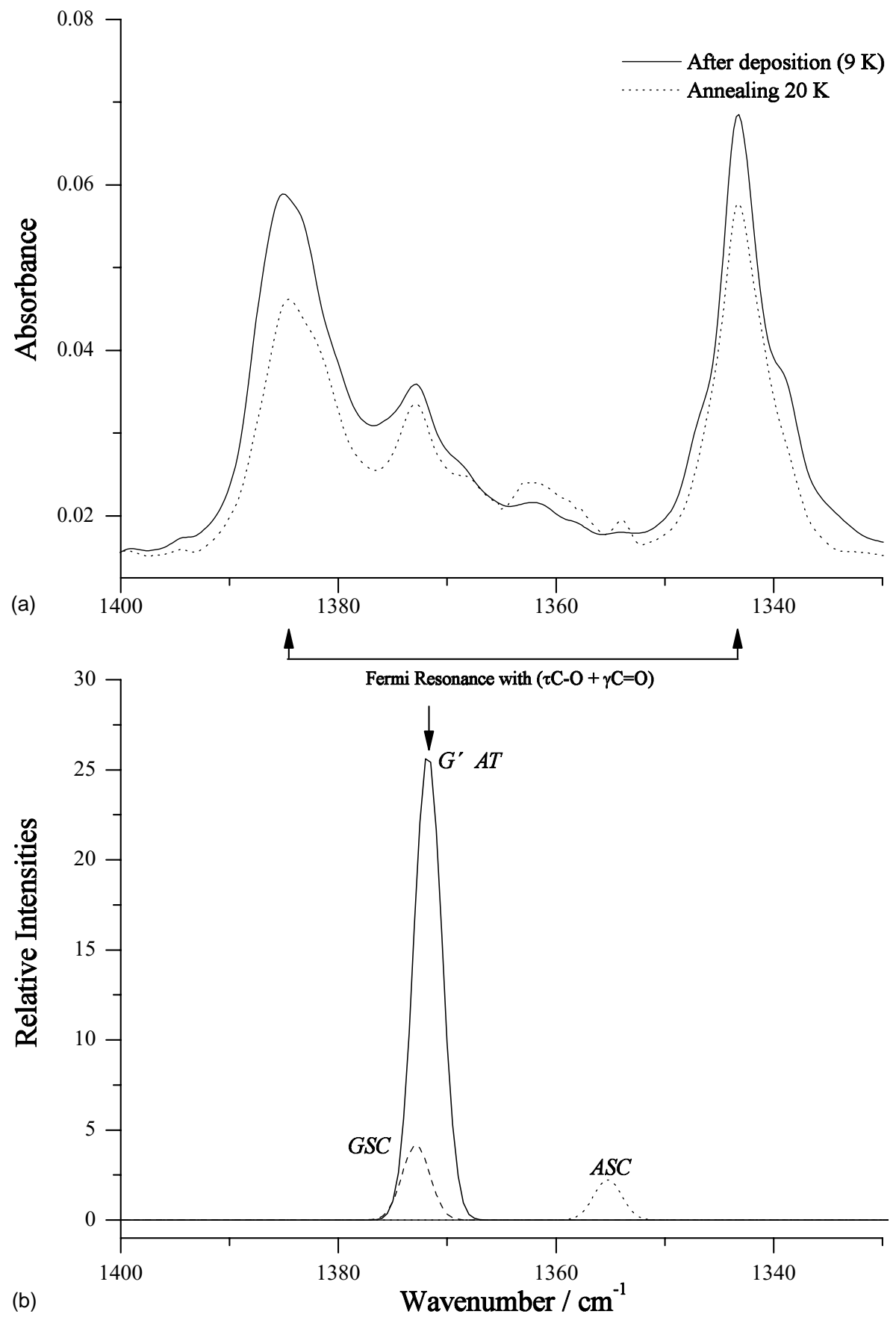

Fig. 6. Comparison of (a) the experimental spectrum (1330-1400 $\mathrm{cm}^{-1}$ region) of matrix-isolated sarcosine (in argon), obtained immediately after deposition at $9 \mathrm{~K}$ (-) and after annealing of the matrix to $20 \mathrm{~K}(---)$, with (b) the DFT(B3LYP)/6-311++G(d, p) calculated spectra for the experimentally observed conformers of sarcosine. Calculated integral intensities were weighted by the relative populations of the different conformers at the sublimation temperature, estimated from the DFT calculated energies. 


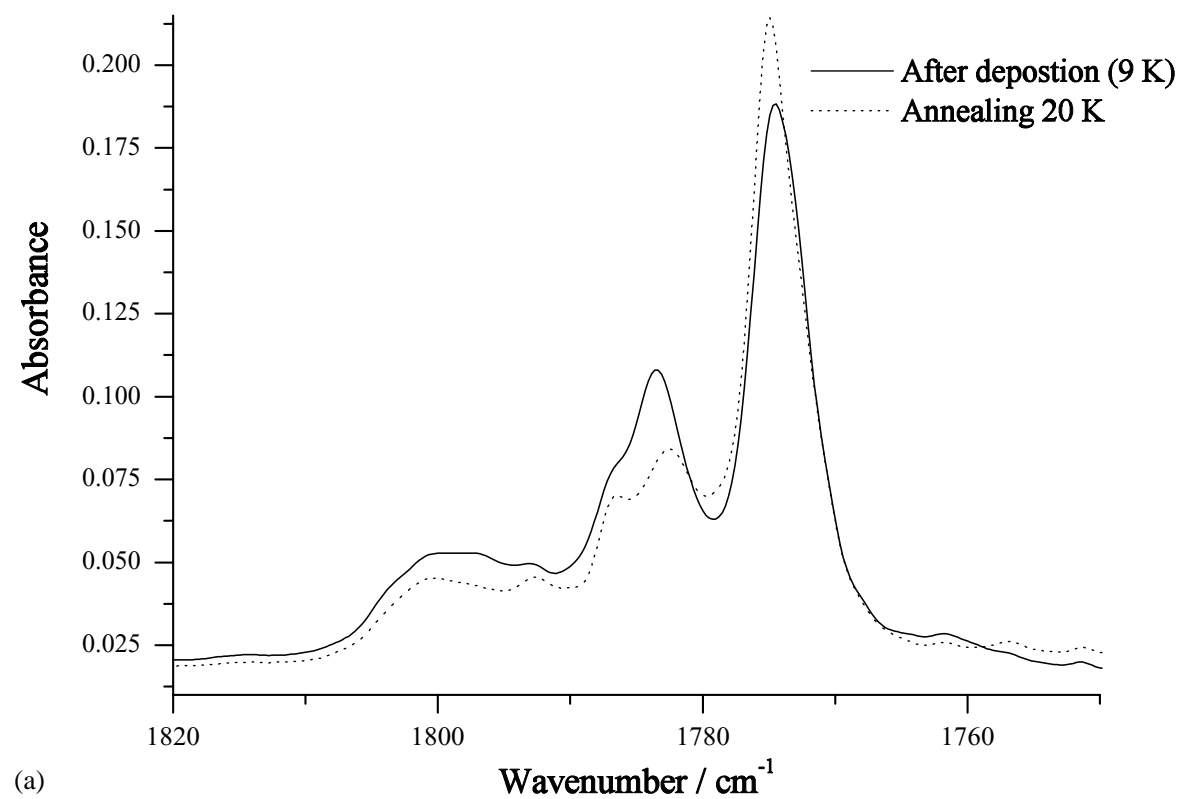

(a)

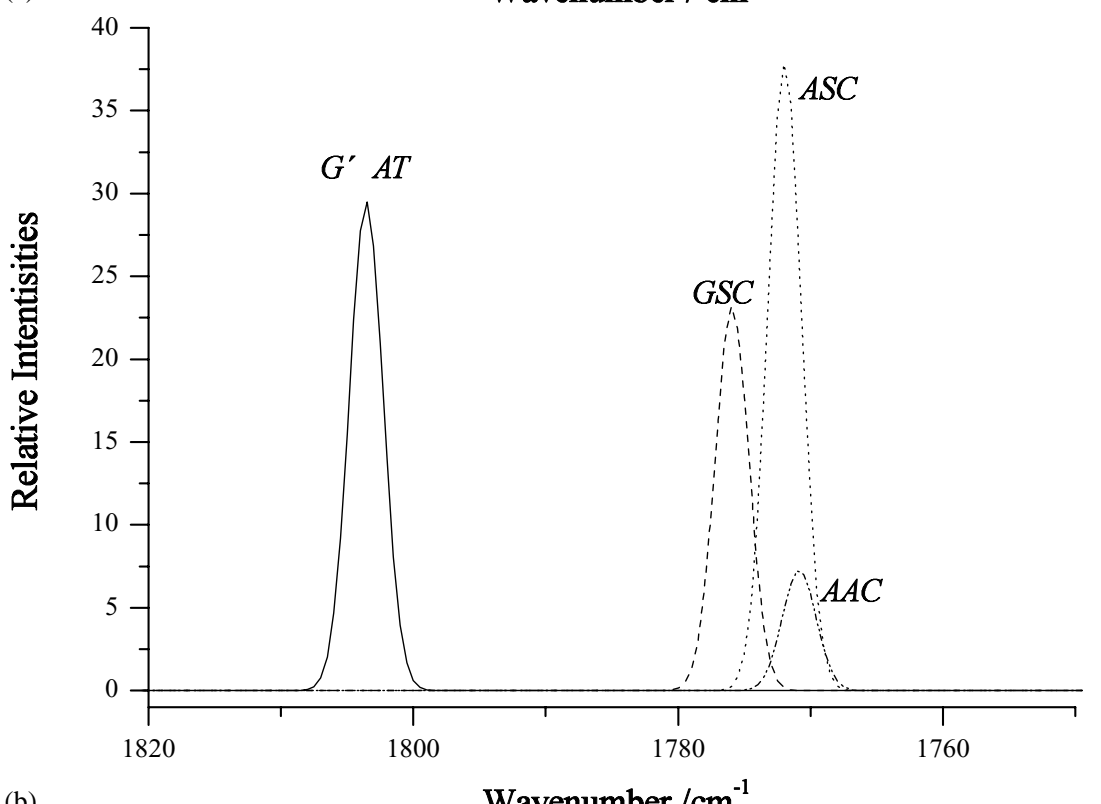

(b)

Wavenumber $/ \mathrm{cm}^{-1}$

Fig. 7. Comparison of (a) the experimental spectrum (carbonyl stretching region) of matrix-isolated sarcosine (in argon), obtained immediately after deposition at $9 \mathrm{~K}(-)$ and after annealing of the matrix to $20 \mathrm{~K}(---)$, with (b) the DFT(B3LYP)/6-311++G(d, p) calculated spectra for the experimentally observed conformers of sarcosine. Calculated integral intensities were weighted by the relative populations of the different conformers at the sublimation temperature, estimated from the DFT calculated energies.

In the carbonyl stretching region (Fig. 7) three main groups of bands were observed, around 1800, 1785 and $1775 \mathrm{~cm}^{-1}$. According to the calculations, the higher frequency group of bands is assigned to $\mathrm{G}^{\prime} \mathrm{AT}$, that appearing near $1785 \mathrm{~cm}^{-1}$ to GSC and the most intense band at $1774 \mathrm{~cm}^{-1}$ (which increases in intensity upon annealing) to the most stable ASC form. The shoulder at ca. $1772 \mathrm{~cm}^{-1}$ is tentatively assigned to AAC. 

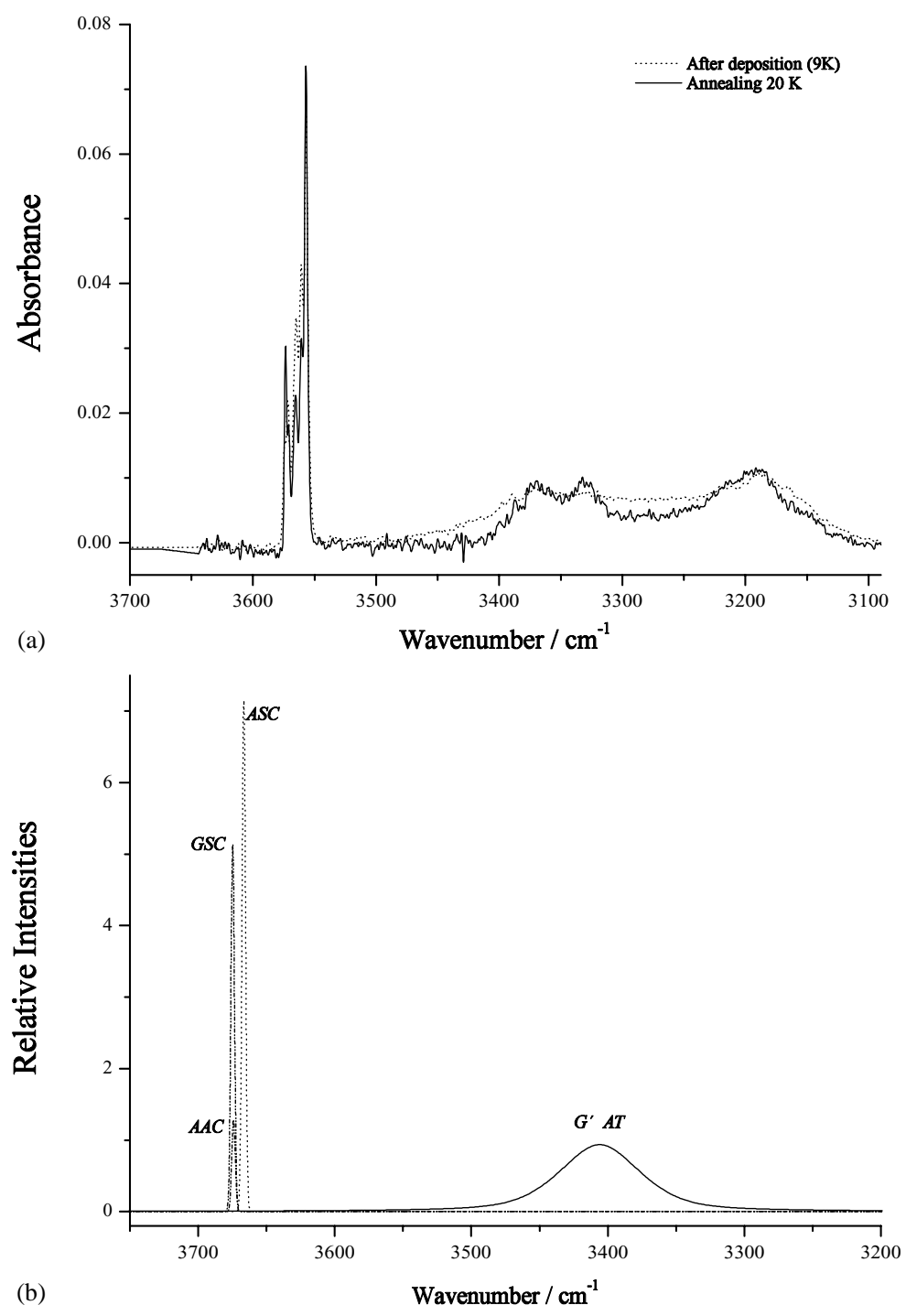

Fig. 8. Comparison of (a) the experimental spectrum ( $\mathrm{OH}$ stretching region) of matrix-isolated sarcosine (in argon), obtained immediately after deposition at $9 \mathrm{~K}$ (-) and after annealing of the matrix to $20 \mathrm{~K}(---)$, with (b) the DFT(B3LYP)/6-311++G(d, p) calculated spectra for the experimentally observed conformers of sarcosine. Calculated integral intensities were weighted by the relative populations of the different conformers at the sublimation temperature, estimated from the DFT calculated energies. The half width of the simulated band of the $\mathrm{G}^{\prime}$ AT conformer was chosen much larger than those of the bands corresponding to the remaining conformers in order to make the simulation resemble more the observed spectra.

Finally, in the hydroxyl stretching region (Fig. 8), the vibration due to the intramolecularly $\mathrm{OH} \cdots \mathrm{N}$ bonded $\mathrm{G}^{\prime} \mathrm{AT}$ form is easily assigned to the intense and broad band observed within 3450 and $3100 \mathrm{~cm}^{-1}$, with relative maxima at 3374,3330 and $3190 \mathrm{~cm}^{-1}$, while the conformers bearing a non-hydrogen-bonded $\mathrm{OH}$ group give rise to the complex multiplet near $3560 \mathrm{~cm}^{-1}$. Bands at 3557 and $3574 \mathrm{~cm}^{-1}$, which increase upon annealing, are due to ASC. We ascribe here the lowest frequency band to $v \mathrm{OH}$ and the highest 
Table 4

Experimental band assignment and calculated [DFT(B3LYP)/6-311++G(d, p)] wavenumbers and intensities, and normal coordinate analysis for sarcosine (ASC conformer) ${ }^{\mathrm{a}}$

\begin{tabular}{|c|c|c|c|c|c|}
\hline \multirow{2}{*}{$\begin{array}{l}\text { Approximate } \\
\text { description }\end{array}$} & \multicolumn{2}{|l|}{ Experimental } & \multicolumn{2}{|l|}{ Calculated } & \multirow[t]{2}{*}{$\mathrm{PED}^{\mathrm{b}}$} \\
\hline & Wavenumber & Intensity & $\begin{array}{l}\text { Wavenumber } \\
\text { (scaled 0.978) }\end{array}$ & Intensity $^{\mathrm{c}}$ & \\
\hline$v \mathrm{O}-\mathrm{H}$ & 3557.2 & 31.0 & 3666.6 & 23.5 & $\mathrm{~S}_{3}(100.1)$ \\
\hline$v \mathrm{~N}-\mathrm{H}$ & & & 3459.7 & 2.2 & $\mathrm{~S}_{9}(99.0)$ \\
\hline$v \mathrm{CH}_{3}$ as $^{\prime \prime}$ & 2994.3 & 5.9 & 3031.0 & 11.6 & $\mathrm{~S}_{12}(88.6)$ \\
\hline$v \mathrm{CH}_{2}$ as & 2970.5 & 4.2 & 3008.6 & 3.1 & $S_{5}(13.9)+S_{6}(86.0)$ \\
\hline$v \mathrm{CH}_{3}$ as $^{\prime}$ & 2957.1 & 6.5 & 2987.2 & 15.0 & $S_{10}(27.1)+S_{11}(61.7)+S_{12}(11.3)$ \\
\hline$v \mathrm{CH}_{2} \mathrm{~s}$ & 2922.6 & 6.4 & 2960.6 & 7.9 & $\mathrm{~S}_{5}(85.9)+\mathrm{S}_{6}(14.0)$ \\
\hline$v \mathrm{CH}_{3} \mathrm{~s}$ & 2988.1 & 6.6 & 2911.4 & 28.4 & $S_{10}(68.1)+S_{11}(31.7)$ \\
\hline$v \mathrm{C}=\mathrm{O}$ & 1774.5 & 79.2 & 1772.0 & 123.8 & $\mathrm{~S}_{1}(86.1)$ \\
\hline$\delta \mathrm{CH}_{3} \mathrm{as}^{\prime \prime}$ & 1486.7 & 5.4 & 1493.6 & 5.3 & $S_{22}(39.1)+S_{25}(43.6)+S_{27}(12.3)$ \\
\hline$\delta \mathrm{NH}$ & 1471.9 & 1.9 & 1470.6 & 0.9 & $\mathrm{~S}_{22}(43.0)+\mathrm{S}_{25}(46.3)$ \\
\hline$\delta \mathrm{CH}_{3}$ as $^{\prime}$ & $1457.9 / 1456.8$ & $5.0 / 3.9$ & 1457.4 & 4.7 & $\mathrm{~S}_{24}(88.6)$ \\
\hline$\delta \mathrm{CH}_{3} \mathrm{~s}$ & $1429.3 / 1427.9$ & $5.1 / 2.6$ & 1430.6 & 3.4 & $\mathrm{~S}_{16}(32.8)+\mathrm{S}_{23}(61.0)$ \\
\hline$\delta \mathrm{CH}_{2}$ & 1411.4 & 7.2 & 1416.5 & 4.5 & $\mathrm{~S}_{16}(63.7)+\mathrm{S}_{23}(34.4)$ \\
\hline$\omega \mathrm{CH}_{2}$ & 1361.5 & 4.5 & 1355.2 & 7.4 & $\mathrm{~S}_{18}(59.4)$ \\
\hline $\mathrm{twCH}_{2}$ & 1297.3 & 3.5 & 1286.3 & 2.4 & $S_{13}(9.6)+S_{19}(48.6)+S_{27}(10.7)$ \\
\hline$\delta \mathrm{COH}$ & 1234.9/1223.8/1220.1 & $2.9 / 3.4 / 5.1$ & 1269.7 & 3.7 & $S_{13}(38.0)+S_{18}(17.4)+S_{19}(13.9)$ \\
\hline$v \mathrm{C}-\mathrm{N}$ & $1182.1 / 1180.2$ & $5.6 / 4.6$ & 1179.2 & 5.1 & $\mathrm{~S}_{7}(41.1)+\mathrm{S}_{8}(10.8)+\mathrm{S}_{27}(13.8)$ \\
\hline$\gamma \mathrm{CH}_{3}^{\prime}$ & $1140.6 / 1138.1$ & $18.8 / 37.4$ & 1132.5 & 45.1 & $\mathrm{~S}_{2}(11.5)+\mathrm{S}_{26}(64.0)$ \\
\hline$v \mathrm{~N}-\mathrm{C}$ & $1134.6 / 1132.3$ & $11.7 / 13.3$ & 1125.0 & 9.0 & $S_{7}(13.8)+S_{8}(28.7)+S_{19}(16.9)+S_{27}(18.4)$ \\
\hline$\nu \mathrm{C}-\mathrm{O}$ & 1109.5 & 74.4 & 1103.6 & 88.1 & $\mathrm{~S}_{2}(40.3)+\mathrm{S}_{13}(18.4)+\mathrm{S}_{26}(20.3)$ \\
\hline$\gamma \mathrm{CH}_{3}^{\prime \prime}$ & $988.3 / 984.6$ & $9.6 / 7.5$ & 976.2 & 5.8 & $\mathrm{~S}_{7}(13.2)+\mathrm{S}_{8}(11.5)+\mathrm{S}_{20}(21.7)+\mathrm{S}_{27}(31.7)$ \\
\hline$\gamma \mathrm{CH}_{2}$ & $938.6 / 936.3$ & $7.5 / \mathrm{sh}$ & 926.8 & 4.6 & $\mathrm{~S}_{8}(36.2)+\mathrm{S}_{20}(29.7)+\mathrm{S}_{32}(15.3)$ \\
\hline$\nu \mathrm{C}-\mathrm{C}$ & 809.0 & 3.5 & 831.7 & 3.9 & $\mathrm{~S}_{4}(52.8)+\mathrm{S}_{17}(12.6)$ \\
\hline Inversion & $\begin{array}{l}744.1 / 741.5 / 736.0 / \\
732.7 / 719.2 / 715.8\end{array}$ & $\begin{array}{l}5.0 / 5.1 / 10.2 / \\
10.1 / 19.1 / 9.4\end{array}$ & 724.1 & 59.3 & $S_{7}(9.7)+S_{21}(16.3)+S_{33}(45.9)$ \\
\hline$\tau \mathrm{C}-\mathrm{O}$ & 623.3 & 58.4 & 641.2 & 44.6 & $\mathrm{~S}_{28}(49.4)+\mathrm{S}_{32}(28.4)$ \\
\hline$\delta \mathrm{OCO}$ & 620.1 & 16.1 & 630.0 & 7.6 & $S_{2}(13.3)+S_{14}(35.4)+S_{15}(12.9)+S_{17}(13.7)$ \\
\hline$\gamma \mathrm{C}=\mathrm{O}$ & 495.4 & 13.0 & 493.6 & 10.9 & $\mathrm{~S}_{20}(16.9)+\mathrm{S}_{28}(40.3)+\mathrm{S}_{32}(36.8)$ \\
\hline$\delta \mathrm{CC}=\mathrm{O}$ & 484.4 & 8.6 & 471.0 & 5.8 & $S_{4}(16.7)+S_{14}(30.6)+S_{15}(13.2)+S_{21}(14.0)$ \\
\hline$\delta \mathrm{CNC}$ & n.i. & & 350.9 & 3.7 & $\mathrm{~S}_{15}(22.5)+\mathrm{S}_{21}(37.8)+\mathrm{S}_{33}(19.1)$ \\
\hline$\delta \mathrm{NCC}$ & n.i. & & 266.5 & 3.4 & $\mathrm{~S}_{15}(27.0)+\mathrm{S}_{17}(21.5)+\mathrm{S}_{31}(39.1)$ \\
\hline$\tau \mathrm{NC}$ & n.i. & & 179.7 & 1.9 & $\mathrm{~S}_{15}(10.2)+\mathrm{S}_{17}(29.0)+\mathrm{S}_{31}(51.2)$ \\
\hline$\tau \mathrm{C}-\mathrm{N}$ & n.i. & & 114.2 & 1.3 & $\mathrm{~S}_{30}(92.8)$ \\
\hline$\tau \mathrm{C}-\mathrm{C}$ & n.i. & & 61.0 & 0.4 & $\mathrm{~S}_{29}(98.8)$ \\
\hline
\end{tabular}

${ }^{\text {a }}$ Wavenumbers in $\mathrm{cm}^{-1}$, calculated intensities in $\mathrm{km} \mathrm{mol}^{-1}$. Experimental normalized intensities $\left(I^{\text {exp }}\right)$ were calculated using the formula: $I_{i}^{\exp }=A_{i}^{\exp }\left(\sum I^{\text {calc }}(x) \times p_{298 \mathrm{~K}}(x) / \sum A^{\exp }\right)$, where $x$ designates conformers ASC, G'AT, GSC and AAC, $p_{298 \mathrm{~K}}$ the population factor at $T=298 \mathrm{~K}$, calculated on the basis of relative energies predicted by DFT calculations, $A^{\text {exp }}$ is the experimentally measure absorbance, and the sums extend to all four conformers and all bands observed (in the denominator of the fraction) or which have an experimental counterpart (in the numerator). sh, shoulder; n.i., non-investigated; $v$, bond stretching; $\delta$, bending; $\gamma$, rocking; tw, twisting; $\omega$, wagging; $\tau$, torsion; s, symmetric; as, asymmetric. See Table 3 for definition of coordinates.

${ }^{\mathrm{b}}$ Only PED values greater than $10 \%$ are given.

${ }^{\mathrm{c}}$ Calculated intensities $\left(I^{\text {calc }} ; \mathrm{km} \mathrm{mol}^{-1}\right)$ were weighed by the population factor $(T=298 \mathrm{~K})$ for the ASC conformer as predicted by the DFT calculations taking into consideration the calculated relative conformational energies $(0.42)$. 
Table 5

Experimental band assignment and calculated [DFT(B3LYP)/6-311++G(d,p)] wavenumbers and intensities, and normal coordinate analysis for sarcosine $\left(\mathrm{G}^{\prime} \mathrm{AT} \text { conformer }\right)^{\mathrm{a}}$

\begin{tabular}{|c|c|c|c|c|c|}
\hline \multirow{2}{*}{$\begin{array}{l}\text { Approximate } \\
\text { description }\end{array}$} & \multicolumn{2}{|l|}{ Experimental } & \multicolumn{2}{|l|}{ Calculated } & \multirow[t]{2}{*}{$\mathrm{PED}^{\mathrm{b}}$} \\
\hline & Wavenumber & Intensity & $\begin{array}{l}\text { Wavenumber } \\
\text { (scaled } 0.978)\end{array}$ & Intensity $^{\mathrm{c}}$ & \\
\hline$v \mathrm{~N}-\mathrm{H}$ & & & 3482.2 & 0.9 & $\mathrm{~S}_{9}(98.7)$ \\
\hline$v \mathrm{O}-\mathrm{H}$ & d & $5.3 / 4.9 / 6.2$ & 3406.2 & 67.9 & $\mathrm{~S}_{3}(98.8)$ \\
\hline$v \mathrm{CH}_{3}$ as $^{\prime \prime}$ & 2998.6 & 5.9 & 3041.9 & 4.6 & $\mathrm{~S}_{12}(93.9)$ \\
\hline$v \mathrm{CH}_{2}$ as & 2983.6 & 4.5 & 3013.1 & 1.8 & $\mathrm{~S}_{5}(11.5)+\mathrm{S}_{6}(88.1)$ \\
\hline$v \mathrm{CH}_{3} \mathrm{as}^{\prime}$ & 2967.4 & 5.5 & 3002.3 & 4.8 & $\mathrm{~S}_{10}(29.0)+\mathrm{S}_{11}(64.5)$ \\
\hline$v \mathrm{CH}_{2} \mathrm{~s}$ & 2918.3 & 6.4 & 2958.6 & 5.6 & $\mathrm{~S}_{5}(88.1)+\mathrm{S}_{6}(11.7)$ \\
\hline$v \mathrm{CH}_{3} \mathrm{~s}$ & 2900.3 & 6.1 & 2917.6 & 15.8 & $\mathrm{~S}_{10}(68.9)+\mathrm{S}_{11}(31.3)$ \\
\hline$v \mathrm{C}=\mathrm{O}$ & $1803.5 / 1799.7 / 1797.7$ & $18.4 / \mathrm{sh} / 18.5$ & 1803.6 & 94.2 & $\mathrm{~S}_{1}(84.5)$ \\
\hline$\delta \mathrm{CH}_{3} \mathrm{as}^{\prime \prime}$ & $1479.9 / 1478.8 / 1476.3$ & $3.2 / 3.9 / 2.7$ & 1484.8 & 3.1 & $\mathrm{~S}_{22}(14.5)+\mathrm{S}_{25}(66.2)+\mathrm{S}_{27}(13.4)$ \\
\hline$\delta \mathrm{CH}_{3}$ as $^{\prime}$ & 1462.8 & 5.2 & 1465.8 & 5.1 & $\mathrm{~S}_{24}(80.0)$ \\
\hline$\delta \mathrm{NH}$ & 1440.7 & 4.0 & 1445.5 & 0.9 & $S_{22}(51.4)+S_{23}(12.1)+S_{25}(19.0)$ \\
\hline$\delta \mathrm{CH}_{2}$ & $1438.2 / 1436.9$ & 4.9 & 1441.2 & 3.1 & $\mathrm{~S}_{16}(50.9)+\mathrm{S}_{22}(12.0)+\mathrm{S}_{23}(24.2)$ \\
\hline$\delta \mathrm{CH}_{3} \mathrm{~s}$ & 1423.8 & 2.2 & 1424.5 & 0.6 & $\mathrm{~S}_{16}(36.9)+\mathrm{S}_{23}(55.5)$ \\
\hline$\delta \mathrm{COH}$ & 1383.4/1343.4(FR)/1385.2 & $21.2 / 25.5$ & 1371.8 & 83.1 & $\mathrm{~S}_{13}(70.9)$ \\
\hline$\omega \mathrm{CH}_{2}$ & 1318.1 & 3.3 & 1319.7 & 2.8 & $\mathrm{~S}_{18}(79.4)$ \\
\hline $\mathrm{twCH}_{2}$ & 1216.5 & 7.1 & 1263.7 & 1.9 & $\mathrm{~S}_{19}(69.5)$ \\
\hline$v \mathrm{C}-\mathrm{O}$ & 1187.6/1176.8 & $4.4 / 3.6$ & 1177.0 & 7.5 & $\mathrm{~S}_{2}(43.4)+\mathrm{S}_{4}(17.5)+\mathrm{S}_{13}(14.6)$ \\
\hline$\gamma \mathrm{CH}_{3}^{\prime \prime}$ & $1148.0 / 1146.3$ & $\mathrm{sh} / 25.3$ & 1145.4 & 2.2 & $\mathrm{~S}_{7}(18.6)+\mathrm{S}_{19}(11.3)+\mathrm{S}_{26}(12.5)+\mathrm{S}_{27}(28.2)$ \\
\hline$\gamma \mathrm{CH}_{3}^{\prime}$ & $1129.2 / 1127.7$ & 13.3 & 1120.3 & 7.5 & $\mathrm{~S}_{26}(50.7)+\mathrm{S}_{27}(10.8)$ \\
\hline$v \mathrm{C}-\mathrm{N}$ & 1106.1 & 74.3 & 1101.5 & 4.1 & $\mathrm{~S}_{7}(23.5)+\mathrm{S}_{8}(35.3)+\mathrm{S}_{19}(9.5)+\mathrm{S}_{26}(15.6)$ \\
\hline$\gamma \mathrm{CH}_{2}$ & $992.4 / 994.3$ & $4.0 / 3.4$ & 981.4 & 1.8 & $S_{7}(11.0)+S_{20}(39.6)+S_{27}(23.5)+S_{32}(9.7)$ \\
\hline$v \mathrm{~N}-\mathrm{C}$ & $920.0 / 924.1$ & $2.9 / 2.1$ & 906.7 & 1.5 & $\mathrm{~S}_{7}(20.1)+\mathrm{S}_{8}(36.7)+\mathrm{S}_{20}(16.3)+\mathrm{S}_{32}(10.5)$ \\
\hline$\nu \mathrm{C}-\mathrm{C}$ & 860.8 & 12.5 & 854.9 & 25.4 & $\mathrm{~S}_{2}(16.3)+\mathrm{S}_{4}(17.3)+\mathrm{S}_{28}(27.0)+\mathrm{S}_{33}(14.4)$ \\
\hline$\tau \mathrm{C}-\mathrm{O}$ & 814.9 & 7.5 & 833.2 & 11.1 & $\mathrm{~S}_{2}(12.5)+\mathrm{S}_{4}(16.5)+\mathrm{S}_{28}(54.1)$ \\
\hline Inversion & $742.9 / 737.1$ & $5.1 / 10.1$ & 740.7 & 1.1 & $\mathrm{~S}_{21}(16.0)+\mathrm{S}_{28}(16.8)+\mathrm{S}_{33}(37.8)$ \\
\hline$\delta \mathrm{OCO}$ & & & 630.4 & 2.2 & $\mathrm{~S}_{14}(40.2)+\mathrm{S}_{17}(18.9)$ \\
\hline$\gamma \mathrm{C}=\mathrm{O}$ & 552.9 & 4.7 & 544.5 & 2.2 & $\mathrm{~S}_{14}(9.8)+\mathrm{S}_{20}(19.1)+\mathrm{S}_{32}(52.7)$ \\
\hline$\delta \mathrm{C}-\mathrm{C}=\mathrm{O}$ & n.i. & & 503.2 & 1.1 & $\mathrm{~S}_{4}(19.5)+\mathrm{S}_{14}(22.2)+\mathrm{S}_{15}(25.4)$ \\
\hline$\delta \mathrm{CNC}$ & n.i. & & 363.2 & 0.5 & $\mathrm{~S}_{21}(50.4)+\mathrm{S}_{33}(20.9)$ \\
\hline$\delta \mathrm{NCC}$ & n.i. & & 316.9 & 4.9 & $\mathrm{~S}_{15}(39.8)+\mathrm{S}_{17}(34.8)+\mathrm{S}_{31}(12.5)$ \\
\hline$\tau \mathrm{NC}$ & n.i. & & 196.8 & 0.2 & $\mathrm{~S}_{17}(12.0)+\mathrm{S}_{31}(82.7)$ \\
\hline$\tau \mathrm{C}-\mathrm{N}$ & n.i. & & 121.4 & 0.2 & $\mathrm{~S}_{29}(43.7)+\mathrm{S}_{30}(47.5)$ \\
\hline$\tau \mathrm{C}-\mathrm{C}$ & n.i. & & 75.1 & 1.2 & $\mathrm{~S}_{29}(47.6)+\mathrm{S}_{30}(43.4)$ \\
\hline
\end{tabular}

${ }^{\text {a }}$ Wavenumbers in $\mathrm{cm}^{-1}$, calculated intensities in $\mathrm{km} \mathrm{mol}^{-1}$. Experimental normalized intensities $\left(I^{\text {exp }}\right)$ were calculated using the formula: $I_{i}^{\exp }=A_{i}^{\exp }\left(\sum I^{\text {calc }}(x) \times p_{298 \mathrm{~K}}(x) / \sum A^{\exp }\right)$, where $x$ designates conformers ASC, G'AT, GSC and AAC, $p_{298 \mathrm{~K}}$ the population factor at $T=298 \mathrm{~K}$, calculated on the basis of relative energies predicted by DFT calculations, $A^{\text {exp }}$ is the experimentally measure absorbance, and the sums extend to all four conformers and all bands observed (in the denominator of the fraction) or which have an experimental counterpart (in the numerator). sh, shoulder; n.i., non-investigated; $v$, bond stretching; $\delta$, bending; $\gamma$, rocking; tw, twisting; $\omega$, wagging; $\tau$, torsion; s, symmetric; as, asymmetric. See Table 3 for definition of coordinates.

${ }^{\mathrm{b}}$ Only PED values greater than $10 \%$ are given.

${ }^{\mathrm{c}}$ Calculated intensities $\left(I^{\mathrm{calc}} ; \mathrm{km} \mathrm{mol}^{-1}\right)$ were weighed by the population factor $(T=298 \mathrm{~K})$ for the $\mathrm{G}^{\prime}$ AT conformer as predicted by the DFT calculations taking into consideration the calculated relative conformational energies $(0.24)$.

${ }^{\mathrm{d}}$ Broad band between 3450 and $3100 \mathrm{~cm}^{-1}$, with maxima at ca. 3190,3330 and $3374 \mathrm{~cm}^{-1}$. 
Table 6

Experimental band assignment and calculated [DFT(B3LYP)/6-311++G(d, p)] wavenumbers and intensities, and normal coordinate analysis for sarcosine (GSC conformer) ${ }^{\mathrm{a}}$

\begin{tabular}{|c|c|c|c|c|c|}
\hline \multirow{2}{*}{$\begin{array}{l}\text { Approximate } \\
\text { description }\end{array}$} & \multicolumn{2}{|l|}{ Experimental } & \multicolumn{2}{|l|}{ Calculated } & \multirow[t]{2}{*}{$\mathrm{PED}^{\mathrm{b}}$} \\
\hline & Wavenumber & Intensity & $\begin{array}{l}\text { Wavenumber } \\
\text { (scaled 0.978) }\end{array}$ & Intensity $^{\mathrm{c}}$ & \\
\hline$v \mathrm{O}-\mathrm{H}$ & $3564.9 / 3566.2$ & $16.9 / 14.6$ & 3674.8 & 16.7 & $\mathrm{~S}_{3}(100.1)$ \\
\hline$v \mathrm{~N}-\mathrm{H}$ & & & 3462.0 & 3.2 & $\mathrm{~S}_{9}(99.2)$ \\
\hline$v \mathrm{CH}_{3} \mathrm{as}^{\prime \prime}$ & & & 3032.6 & 5.9 & $\mathrm{~S}_{12}(86.5)$ \\
\hline$v \mathrm{CH}_{2}$ as & & & 2985.3 & 3.2 & $S_{5}(45.1)+S_{6}(54.6)$ \\
\hline$v \mathrm{CH}_{3}$ as $^{\prime}$ & 2949.4 & 6.0 & 2979.9 & 9.0 & $\mathrm{~S}_{10}(40.8)+\mathrm{S}_{11}(45.3)+\mathrm{S}_{12}(13.6)$ \\
\hline$v \mathrm{CH}_{3} \mathrm{~s}$ & 2861.6 & 5.4 & 2865.7 & 25.7 & $\mathrm{~S}_{10}(52.9)+\mathrm{S}_{11}(47.3)$ \\
\hline$v \mathrm{CH}_{2} \mathrm{~s}$ & 2807.0 & 5.3 & 2827.0 & 14.8 & $\mathrm{~S}_{5}(54.8)+\mathrm{S}_{6}(45.4)$ \\
\hline$v \mathrm{C}=\mathrm{O}$ & $1786.4 / 1783.5$ & $30.6 / 43.3$ & 1775.9 & 74.1 & $\mathrm{~S}_{1}(85.2)$ \\
\hline$\delta \mathrm{CH}_{3} \mathrm{as}^{\prime \prime}$ & 1481.2 & 3.2 & 1486.4 & 4.5 & $S_{22}(36.4)+S_{25}(41.5)+S_{27}(11.3)$ \\
\hline$\delta \mathrm{NH}$ & 1473.4 & 1.9 & 1474.5 & 0.4 & $S_{16}(16.9)+S_{22}(22.4)+S_{24}(20.8)$ \\
\hline$\delta \mathrm{CH}_{3}$ as $^{\prime}$ & 1453.4 & $\mathrm{sh}$ & 1455.9 & 1.6 & $S_{16}(10.6)+S_{22}(12.3)+S_{24}(38.3)$ \\
\hline$\delta \mathrm{CH}_{2}$ & 1452.6 & 6.8 & 1452.6 & 3.5 & $S_{16}(64.5)+S_{24}(28.5)+S_{25}(17.9)$ \\
\hline$\delta \mathrm{CH}_{3} \mathrm{~s}$ & 1425.7 & 2.4 & 1427.2 & 1.1 & $\mathrm{~S}_{23}(89.9)+\mathrm{S}_{25}(28.9)$ \\
\hline$\omega \mathrm{CH}_{2}$ & 1373.0 & 10.9 & 1372.9 & 13.3 & $\mathrm{~S}_{2}(9.8)+\mathrm{S}_{4}(11.5)+\mathrm{S}_{18}(39.7)$ \\
\hline$\delta \mathrm{COH}$ & 1261.8 & 3.2 & 1281.3 & 3.5 & $S_{13}(43.6)+S_{14}(10.2)+S_{18}(27.0)$ \\
\hline $\mathrm{twCH}_{2}$ & & & 1226.7 & 0.8 & $S_{7}(11.4)+S_{19}(55.8)+S_{27}(15.1)+S_{22}(11.8)$ \\
\hline$v \mathrm{C}-\mathrm{N}$ & 1195.7 & 3.0 & 1191.5 & 6.9 & $\mathrm{~S}_{7}(23.0)+\mathrm{S}_{19}(27.5)+\mathrm{S}_{27}(12.1)$ \\
\hline$v \mathrm{~N}-\mathrm{C}$ & $1148.2 / 1146.3$ & $\operatorname{sh} / 26.0$ & 1142.8 & 45.3 & $\mathrm{~S}_{2}(13.2)+\mathrm{S}_{7}(17.8)+\mathrm{S}_{8}(39.2)$ \\
\hline$\gamma \mathrm{CH}_{3}{ }^{\prime}$ & 1127.7 & 13.5 & 1119.5 & 2.0 & $\mathrm{~S}_{8}(13.7)+\mathrm{S}_{26}(58.5)$ \\
\hline$v \mathrm{C}-\mathrm{O}$ & 1116.7/1113.9/1111.8 & $25.1 / 28.9$ & 1114.6 & 29.8 & $\mathrm{~S}_{2}(28.8)+\mathrm{S}_{13}(15.1)+\mathrm{S}_{26}(11.2)+\mathrm{S}_{26}(10.2)$ \\
\hline$\gamma \mathrm{CH}_{2}$ & 996.2 & 2.8 & 983.8 & 0.1 & $\mathrm{~S}_{20}(64.8)+\mathrm{S}_{32}(19.2)$ \\
\hline$\gamma \mathrm{CH}_{3}^{\prime \prime}$ & $986.8 / 983.1$ & $7.6 / 9.4$ & 974.0 & 7.3 & $\left.S_{7(} 20.4\right)+S_{8}(27.0)+S_{27}(26.1)+S_{26}(12.4)$ \\
\hline$v \mathrm{C}-\mathrm{C}$ & 895.2 & 2.2 & 872.9 & 4.7 & $\mathrm{~S}_{2}(10.7)+\mathrm{S}_{4}(49.5)$ \\
\hline Inversion & $726.6 / 722.4$ & $19.5 / 21.6$ & 731.8 & 23.3 & $S_{21}(17.5)+S_{33}(61.6)$ \\
\hline$\gamma \mathrm{C}=\mathrm{O}$ & 643.9 & 4.6 & 652.4 & 17.4 & $\mathrm{~S}_{28}(33.1)+\mathrm{S}_{32}(41.1)$ \\
\hline$\delta \mathrm{OCO}$ & & & 624.1 & 11.8 & $\mathrm{~S}_{2}(10.8)+\mathrm{S}_{14}(46.4)+\mathrm{S}_{28}(15.9)$ \\
\hline$\tau \mathrm{C}-\mathrm{O}$ & 519.4 & 3.9 & 515.9 & 6.0 & $\mathrm{~S}_{28}(50.1)+\mathrm{S}_{32}(28.4)$ \\
\hline$\delta \mathrm{C}-\mathrm{C}=\mathrm{O}$ & n.i. & & 432.4 & 2.9 & $\mathrm{~S}_{14}(13.6)+\mathrm{S}_{15}(51.1)$ \\
\hline$\delta \mathrm{CNC}$ & n.i. & & 352.4 & 1.0 & $S_{4}(13.7)+S_{17}(11.5)+S_{21}(34.8)$ \\
\hline$\tau \mathrm{NC}$ & n.i. & & 242.1 & 0.4 & $\mathrm{~S}_{31}(86.6)$ \\
\hline$\delta \mathrm{NCC}$ & n.i. & & 190.5 & 0.6 & $S_{15}(19.1)+S_{17}(43.1)+S_{21}(15.2)+S_{33}(17.4)$ \\
\hline$\tau \mathrm{C}-\mathrm{N}$ & n.i. & & 94.8 & 0.7 & $\mathrm{~S}_{29}(35.1)+\mathrm{S}_{30}(59.0)$ \\
\hline$\tau \mathrm{C}-\mathrm{C}$ & n.i. & & 82.7 & 0.3 & $\mathrm{~S}_{29}(61.0)+\mathrm{S}_{30}(38.7)$ \\
\hline
\end{tabular}

${ }^{\text {a }}$ Wavenumbers in $\mathrm{cm}^{-1}$, calculated intensities in $\mathrm{km} \mathrm{mol}^{-1}$. Experimental normalized intensities $\left(I^{\text {exp }}\right)$ were calculated using the formula: $I_{i}^{\exp }=A_{i}^{\exp }\left(\sum I^{\text {calc }}(x) \times p_{298 \mathrm{~K}}(x) / \sum A^{\exp }\right)$, where $x$ designates conformers ASC, G'AT, GSC and AAC, $p_{298 \mathrm{~K}}$ the population factor at $T=298 \mathrm{~K}$, calculated on the basis of relative energies predicted by DFT calculations, $A^{\text {exp }}$ is the experimentally measure absorbance, and the sums extend to all four conformers and all bands observed (in the denominator of the fraction) or which have an experimental counterpart (in the numerator). sh, shoulder; n.i., non-investigated; $v$, bond stretching; $\delta$, bending; $\gamma$, rocking; tw, twisting; $\omega$, wagging; $\tau$, torsion; s, symmetric; as, asymmetric. See Table 3 for definition of coordinates.

${ }^{\mathrm{b}}$ Only PED values greater than $10 \%$ are given.

${ }^{\mathrm{c}}$ Calculated intensities $\left(I^{\mathrm{calc}} ; \mathrm{km} \mathrm{mol}^{-1}\right)$ were weighed by the population factor $(T=298 \mathrm{~K})$ for the GSC conformer as predicted by the DFT calculations taking into consideration the calculated relative conformational energies $(0.23)$.

frequency band to the carbonyl stretching overtone of this conformer. The remaining bands decrease of intensity upon annealing and are due to the $v \mathrm{OH}$ vibration of $\operatorname{GSC}\left(3565 \mathrm{~cm}^{-1} / 3566 \mathrm{~cm}^{-1}\right)$ and AAC $\left(3561 \mathrm{~cm}^{-1}\right)$.
The general description of the experimental data, in terms of the DFT calculated spectra for the different conformers weighted by their DFT estimated relative populations at the temperature of 
Table 7

Experimental band assignment and calculated [DFT(B3LYP)/6-311++G(d,p)] wavenumbers and intensities, and normal coordinate analysis for sarcosine (AAC conformer) ${ }^{\mathrm{a}}$

\begin{tabular}{|c|c|c|c|c|c|}
\hline \multirow{2}{*}{$\begin{array}{l}\text { Approximate } \\
\text { description }\end{array}$} & \multicolumn{2}{|l|}{ Experimental } & \multicolumn{2}{|l|}{ Calculated } & \multirow[t]{2}{*}{$\mathrm{PED}^{\mathrm{b}}$} \\
\hline & Wavenumber & Intensity & $\begin{array}{l}\text { Wavenumber } \\
\text { (scaled } 0.978 \text { ) }\end{array}$ & Intensity $^{\mathrm{c}}$ & \\
\hline$v \mathrm{O}-\mathrm{H}$ & 3561.0 & 20.8 & 3674.2 & 4.2 & $\mathrm{~S}_{3}(100.1)$ \\
\hline$v \mathrm{~N}-\mathrm{H}$ & & & 3471.4 & 0.3 & $\mathrm{~S}_{9}(99.1)$ \\
\hline$v \mathrm{CH}_{3} \mathrm{as}^{\prime \prime}$ & & & 3032.1 & 1.6 & $\mathrm{~S}_{12}(91.4)$ \\
\hline$v \mathrm{CH}_{2}$ as & & & 3023.0 & 0.5 & $\mathrm{~S}_{5}(16.4)+\mathrm{S}_{6}(83.2)$ \\
\hline$v \mathrm{CH}_{3} \mathrm{as}^{\prime}$ & & & 2986.9 & 2.1 & $\mathrm{~S}_{10}(36.8)+\mathrm{S}_{11}(55.0)$ \\
\hline$v \mathrm{CH}_{2} \mathrm{~s}$ & & & 2963.9 & 1.1 & $\mathrm{~S}_{5}(83.5)+\mathrm{S}_{6}(16.5)$ \\
\hline$v \mathrm{CH}_{3} \mathrm{~s}$ & 2871.9 & 5.4 & 2892.7 & 4.7 & $\mathrm{~S}_{10}(59.5)+\mathrm{S}_{11}(40.5)$ \\
\hline$v \mathrm{C}=\mathrm{O}$ & 1772.0 & $\mathrm{sh}$ & 1770.9 & 19.9 & $\mathrm{~S}_{1}(86.5)$ \\
\hline$\delta \mathrm{CH}_{3}$ as $^{\prime \prime}$ & & & 1490.5 & 16.6 & $S_{22}(36.7)+S_{25}(47.0)+S_{27}(12.7)$ \\
\hline$\delta \mathrm{NH}$ & & & 1466.9 & 0.2 & $\mathrm{~S}_{22}(45.6)+\mathrm{S}_{25}(42.3)$ \\
\hline$\delta \mathrm{CH}_{3}$ as & & & 1458.2 & 0.6 & $\mathrm{~S}_{24}(81.9)$ \\
\hline$\delta \mathrm{CH}_{3} \mathrm{~s}$ & & & 1429.1 & 0.3 & $S_{16}(35.6)+S_{23}(57.0)$ \\
\hline$\delta \mathrm{CH}_{2}$ & 1419.4 & 2.2 & 1418.6 & 0.1 & $\mathrm{~S}_{16}(62.0)+\mathrm{S}_{23}(33.6)$ \\
\hline$\omega \mathrm{CH}_{2}$ & 1325.6 & 2.6 & 1326.0 & 0.6 & $\mathrm{~S}_{18}(87.3)$ \\
\hline$\delta \mathrm{COH}$ & 1314.5 & 2.6 & 1311.0 & 2.0 & $S_{2}(16.1)+S_{13}(29.9)+S_{14}(13.4)+S_{19}(16.4)$ \\
\hline $\mathrm{twCH}_{2}$ & & & 1279.3 & 0.1 & $S_{13}(13.3)+S_{19}(47.5)+S_{27}(12.6)$ \\
\hline$v \mathrm{C}-\mathrm{N}$ & & & 1179.2 & 2.7 & $\mathrm{~S}_{7}(21.6)+\mathrm{S}_{27}(20.0)$ \\
\hline$v \mathrm{~N}-\mathrm{C}$ & 1150.9 & 13.3 & 1149.0 & 7.1 & $S_{2}(11.1)+S_{7}(25.4)+S_{8}(24.5)+S_{13}(17.9)+S_{26}(10.0)$ \\
\hline$\gamma \mathrm{CH}_{3}^{\prime}$ & 1127.7 & $\operatorname{sh}$ & 1125.0 & 0.2 & $\mathrm{~S}_{26}(70.7)$ \\
\hline$v \mathrm{C}-\mathrm{O}$ & 1101.1 & $\mathrm{sh}$ & 1099.2 & 7.0 & $S_{2}(21.7)+S_{8}(10.0)+S_{13}(12.8)+S_{19}(14.0)+S_{27}(13.4)$ \\
\hline$\gamma \mathrm{CH}_{3}^{\prime \prime}$ & 980.2 & 3.5 & 969.7 & 0.6 & $\mathrm{~S}_{7}(14.0)+\mathrm{S}_{8}(10.4)+\mathrm{S}_{20}(23.4)+\mathrm{S}_{27}(31.3)$ \\
\hline$\gamma \mathrm{CH}_{2}$ & 933.7 & 2.4 & 923.2 & 0.5 & $\mathrm{~S}_{7}(10.5)+\mathrm{S}_{8}(34.3)+\mathrm{S}_{20}(28.3)+\mathrm{S}_{32}(16.4)$ \\
\hline$v \mathrm{C}-\mathrm{C}$ & 803.6 & $\operatorname{sh}$ & 819.2 & 1.3 & $\mathrm{~S}_{2}(33.7)+\mathrm{S}_{4}(38.6)$ \\
\hline Inversion & 713.4 & 8.5 & 716.9 & 8.0 & $S_{21}(16.1)+S_{33}(45.5)$ \\
\hline$\gamma \mathrm{C}=\mathrm{O}$ & 662.6 & 3.3 & 664.6 & 5.7 & $\mathrm{~S}_{20}(10.0)+\mathrm{S}_{28}(35.5)+\mathrm{S}_{32}(31.8)$ \\
\hline$\tau \mathrm{C}-\mathrm{O}$ & $602.2 / 598.9$ & $5.6 / 5.6$ & 600.5 & 4.0 & $\mathrm{~S}_{14}(32.2)+\mathrm{S}_{17}(13.6)+\mathrm{S}_{28}(34.1)$ \\
\hline$\delta \mathrm{OCO}$ & n.i. & & 515.4 & 1.6 & $S_{4}(20.6)+S_{14}(33.6)+S_{28}(16.4)+S_{32}(12.5)$ \\
\hline$\delta \mathrm{CC}=\mathrm{O}$ & n.i. & & 470.8 & 0.2 & $\mathrm{~S}_{15}(21.2)+\mathrm{S}_{17}(9.8)+\mathrm{S}_{28}(12.7)+\mathrm{S}_{32}(20.3)$ \\
\hline$\delta \mathrm{CNC}$ & n.i. & & 357.2 & 0.4 & $\mathrm{~S}_{15}(23.0)+\mathrm{S}_{21}(42.5)+\mathrm{S}_{33}(18.6)$ \\
\hline$\delta \mathrm{NCC}$ & n.i. & & 267.8 & 0.2 & $\mathrm{~S}_{15}(24.8)+\mathrm{S}_{17}(19.4)+\mathrm{S}_{31}(34.8)$ \\
\hline$\tau \mathrm{NC}$ & n.i. & & 181.7 & 0.0 & $\mathrm{~S}_{17}(24.4)+\mathrm{S}_{31}(57.4)$ \\
\hline$\tau \mathrm{C}-\mathrm{N}$ & n.i. & & 124.2 & 0.1 & $\mathrm{~S}_{30}(90.6)$ \\
\hline$\tau \mathrm{C}-\mathrm{C}$ & n.i. & & 49.1 & 0.1 & $\mathrm{~S}_{29}(106.2)$ \\
\hline
\end{tabular}

${ }^{\text {a }}$ Wavenumbers in $\mathrm{cm}^{-1}$, calculated intensities in $\mathrm{km} \mathrm{mol}^{-1}$. Experimental normalized intensities $\left(I^{\text {exp }}\right)$ were calculated using the formula: $I_{i}^{\exp }=A_{i}^{\exp }\left(\sum I^{\text {calc }}(x) \times p_{298 \mathrm{~K}}(x) / \sum A^{\exp }\right)$, where $x$ designates conformers ASC, G'AT, GSC and AAC, $p_{298 \mathrm{~K}}$ the population factor at $T=298 \mathrm{~K}$, calculated on the basis of relative energies predicted by DFT calculations, $A^{\text {exp }}$ is the experimentally measure absorbance, and the sums extend to all four conformers and all bands observed (in the denominator of the fraction) or which have an experimental counterpart (in the numerator). sh, shoulder; n.i., non-investigated; $v$, bond stretching; $\delta$, bending; $\gamma$, rocking; tw, twisting; $\omega$, wagging; $\tau$, torsion; s, symmetric; as, asymmetric. See Table 3 for definition of coordinates.

${ }^{\mathrm{b}}$ Only PED values greater than $10 \%$ are given.

${ }^{\mathrm{c}}$ Calculated intensities $\left(I^{\mathrm{calc}} ; \mathrm{km} \mathrm{mol}^{-1}\right)$ were weighed by the population factor $(T=298 \mathrm{~K})$ for the AAC conformer as predicted by the DFT calculations taking into consideration the calculated relative conformational energies $(0.06)$.

sublimation of the compound prior to matrix deposition, follows the good agreement observed in the case of the above discussed (most intense) spectral regions. It can then be concluded that in the gaseous phase sarcosine exists as a mixture of four conformers with observable populations, the relative stabilities of these conformers being well predicted by the DFT(B3LYP)/6-311++G(d, p) calculations. 


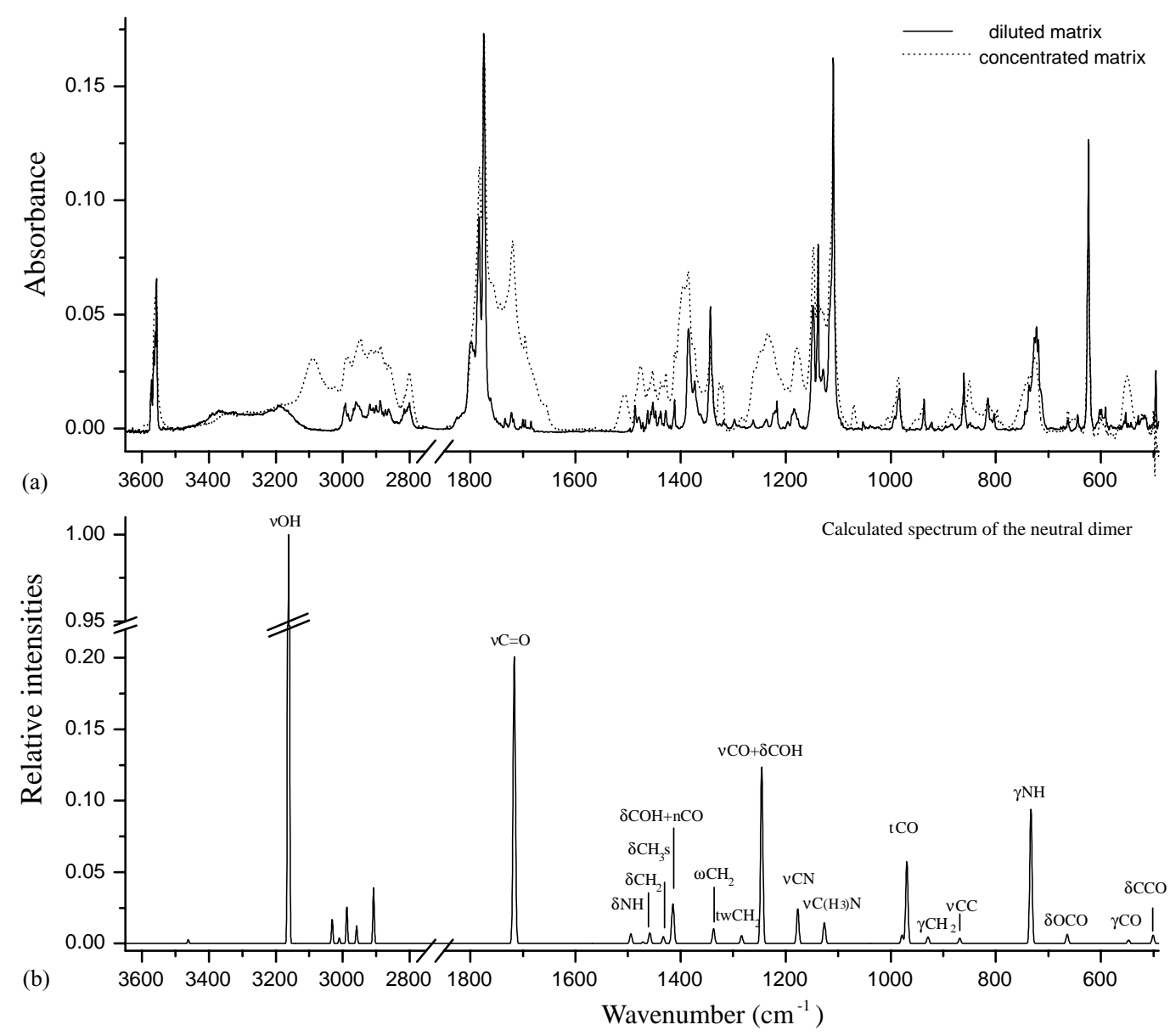

Fig. 9. Comparison of the spectra of (a) sarcosine isolated in an argon matrix ((-) diluted matrix; (- - -) concentrated matrix) at 9 K, with (b) the DFT(B3LYP)/6-311++G(d, p) calculated IR spectrum for the carboxylic-like sarcosine dimer with monomeric units in the ASC conformation (the calculated frequencies were multiplied by the scale factor 0.978).

The results also indicated that all these four conformers could be trapped without significant conformational cooling in an argon matrix when the substrate of the cryostat was kept at $9 \mathrm{~K}$ during matrix deposition.

In a final experiment, sarcosine was deposited in the same way as in the previous experiments, but the temperature of the substrate of the cryostat was increased up to $15 \mathrm{~K}$. Fig. 10 compares several relevant regions of the spectrum obtained immediately after deposition at this temperature with that obtained when the deposition was made with the substrate at $9 \mathrm{~K}$. It is clear from this figure that, when the temperature of the substrate was increased, the higher energy conformers partially convert to the most stable form during the landing of the molecules onto the surface of the cold substrate. This type of phenomenon (conformational cooling) has been observed in other systems with relatively low energy barriers for conformational interconversion [27-30] and, for such kind of systems, shall be taken into consideration when temperatures of deposition are relatively high. A detailed analysis of conformational cooling effects in matrix-isolation spectroscopy can be found elsewhere [30]. 

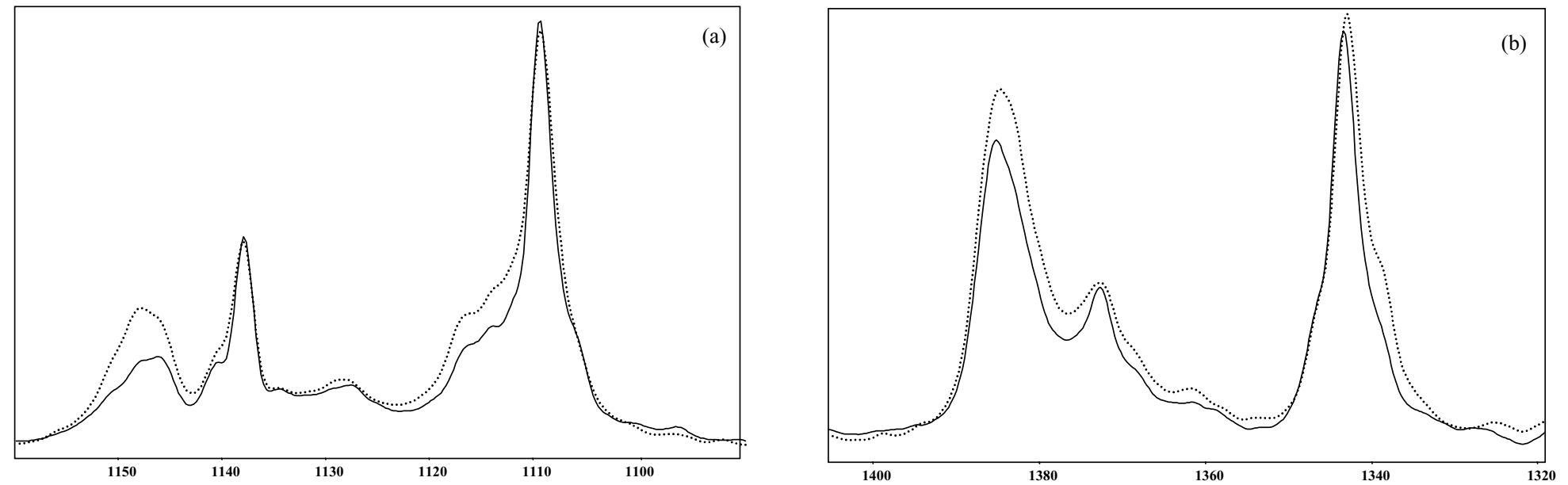

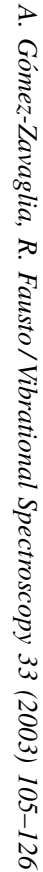
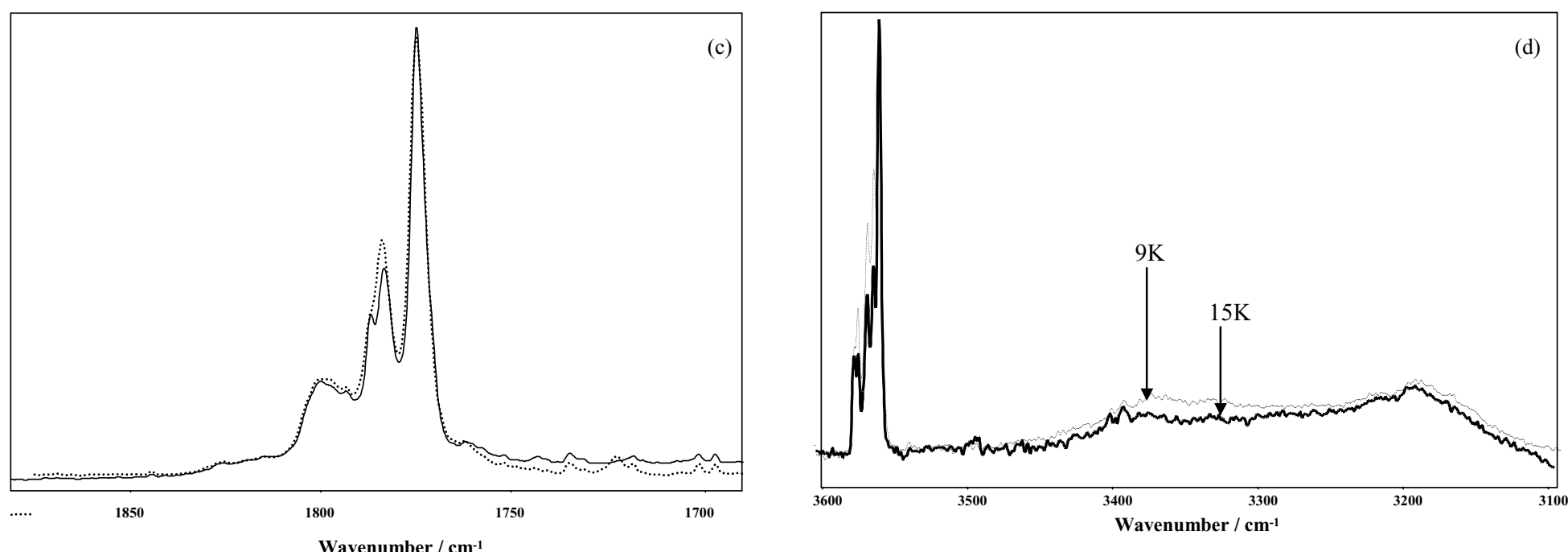

Fig. 10. Comparison of the experimental spectrum of matrix-isolated sarcosine (in argon), obtained immediately after deposition at $9 \mathrm{~K}$ (- - -) and immediately after deposition at $15 \mathrm{~K}$ (一). (a) $1080-2160 \mathrm{~cm}^{-1}$ region; (b) $1330-1400 \mathrm{~cm}^{-1}$; (c) carbonyl stretching region and (d) $v \mathrm{OH}$ region. Intensities were normalized to the bands of the most stable form (ASC) 


\section{Conclusion}

Matrix-isolated infrared spectroscopy supported by theoretical predictions undertaken at the DFT(B3LYP)/ 6-311++ $\mathrm{G}^{* *}$ and MP2/6-31++ $\mathrm{G}^{* *}$ levels of theory allowed, for the first time, unequivocal observation and spectral signature characterization of four conformers of sarcosine. Assignment of the observed spectra (in argon) was carried out on the basis of comparison with the theoretical spectra, annealing experiments and substrate temperature variation data.

The conformational ground state was found to be the intramolecularly $\mathrm{N}-\mathrm{H} \cdots \mathrm{O}=$ hydrogen-bonded ASC form, similar to glycine most stable conformer [9], where the carboxylic group assumes the cis configuration and the $\mathrm{O}=\mathrm{C}-\mathrm{C}-\mathrm{N}$ and $\mathrm{Lp}-\mathrm{N}-\mathrm{C}-\mathrm{C}$ (where $\mathrm{Lp}$ is the nitrogen lone electron pair) dihedral angles are ca. 15 and $-8^{\circ}$, respectively. The second most stable conformer $\left(\mathrm{G}^{\prime} \mathrm{AT}\right)$ exhibits a strong $\mathrm{OH} \cdots \mathrm{N}$ intramolecular hydrogen bond and a trans carboxylic group, being similar to the most stable form of $N, N$ dimethylglycine [11]. These two forms were predicted to differ in energy by less than ca. $2 \mathrm{~kJ} \mathrm{~mol}^{-1}$ and represent $\approx 70 \%$ of the conformational population of the gas at room temperature. Conformers GSC and AAC could also be identified experimentally and characterized vibrationally.

\section{Acknowledgements}

This work was supported by the Portuguese Fundação para a Ciência e a Tecnologia (Research Project POCTI/QUI/43366/2001 and Grant FCT \#SFRH/BPD/11499/2002) and FEDER.

\section{References}

[1] N. von Weymarn, A. Nyyssölä, T. Reinikainen, M. Leisola, H. Ojamo, Appl. Microbiol. Biotechnol. 55 (2001) 214.

[2] M.L. Mendum, L.T. Smith, Appl. Environ. Microbiol. 68 (2002) 813.

[3] T. van Der Heide, B. Poolman, J. Bacteriol. 182 (2000) 203.

[4] G. Barone, P. Del Vecchio, D. Esposito, D. Fessas, G. Graziano, J. Chem. Soc., Faraday Trans. 92 (1996) 1361.

[5] T.J. Anchordoguy, A.S. Rudolph, J.F. Carpenter, J.H. Crowe, Cryobiology 24 (1987) 324.
[6] A.W. Lloyd, J.A. Baker, G. Smith, C.J. Olliff, K.J. Rutt, J. Pharm. Pharmacol. 44 (1992) 507.

[7] A.W. Lloyd, C.J. Olliff, K.J. Rutt, J. Pharm. Pharmacol. 46 (1994) 704.

[8] J. Higgins, N.A. Hodges, C.J. Olliff, A.J. Phillips, J. Pharm. Pharmacol. 39 (1987) 577.

[9] S.G. Stepanian, I.D. Reva, E.D. Radchenko, M.T.S. Rosado, M.L.T.S. Duarte, R. Fausto, L. Adamowicz, J. Phys. Chem. 102 (1998) 1041.

[10] S.G. Stepanian, I.D. Reva, E.D. Radchenko, L. Adamowicz, J. Phys. Chem. A 105 (2001) 664.

[11] A. Gómez Zavaglia, I. Reva, R. Fausto, Phys. Chem. Chem. Phys. 5 (2003) 41.

[12] A. Headley, S. Starnes, J. Mol. Struct. (Teochem.) 370 (1996) 147.

[13] A.D. Headley, S.D. Starnes, J. Mol. Struct. 467 (1999) 95.

[14] A. Mostad, S. Natarajan, Acta Chem. Scan. 43 (1989) 1004.

[15] M. Frisch, G. Trucks, H. Schlegel, G. Scuseria, M. Robb, J. Cheeseman, V. Zakrzewski, J. Montgomery, R. Stratmann, K. Burant, S. Dapprich, J. Millam, A. Daniels, K. Kudin, M. Strain, O. Farkas, J. Tomasi, V. Barone, M. Cossi, R. Cammi, B. Mennucci, C. Pomelli, C. Adamo, S. Clifford, J. Ochterski, G. Petersson, P. Ayala, Q. Cui, K. Morokuma, D. Malick, A. Rabuck, K. Raghavachari, J. Foresman, J. Cioslowski, J. Ortiz, A. Baboul, B. Stefanov, G. Liu, A. Liashenko, P. Piskorz, I. Komaromi, R. Gomperts, R. Martin, D. Fox, T. Keith, M. Al-Laham, C. Peng, A. Nanayakkara, M. Challacombe, P. Gill, B. Johnson, W. Chen, M. Wong, J. Andres, C. Gonzalez, M. Head-Gordon, S. Replogle, J. Pople, Gaussian 98, Revision A.9, Gaussian Inc., Pittsburgh, PA, 1998.

[16] M.J. Frisch, M. Head-Gordon, J.A. Pople, Chem. Phys. Lett. 166 (1990) 281.

[17] R. Ditchfield, W.J. Hehre, J.A. Pople, J. Chem. Phys. 54 (1971) 724.

[18] A.D. Becke, Phys. Rev. A 38 (1988) 3098.

[19] C.T. Lee, W.T. Yang, R.G. Parr, Phys. Rev. B 37 (1988) 785.

[20] S.H. Vosko, L. Wilk, M. Nusair, Can. J. Phys. 58 (1980) 1200.

[21] P. Csaszar, P. Pulay, J. Mol. Struct. (Theochem.) 114 (1984) 31.

[22] J.H. Schachtschneider, Technical Report, Shell Development Co., Emeryville, CA, 1969.

[23] C. Peng, H.B. Schlegel, Israel J. Chem. 33 (1994) 449.

[24] R. Fausto, J. Mol. Struct. (Theochem.) 315 (1994) 123.

[25] R. Fausto, L.A.E. Batista de Carvalho, J.J.C. Teixeira-Dias, J. Comput. Chem. 13 (1992) 799.

[26] J.J.C. Teixeira-Dias, R. Fausto, L.A.E. Batista de Carvalho, J. Mol. Struct. (Theochem.) 262 (1992) 87.

[27] A. Gómez-Zavaglia, R. Fausto, Phys. Chem. Chem. Phys. 5 (2003) 41.

[28] S.B. Lopes, L. Lapinski, R. Fausto, Phys. Chem. Chem. Phys. 4 (2002) 1014.

[29] I.D. Reva, S.V. Ilieva, R. Fausto, Phys. Chem. Chem. Phys. 3 (2001) 4235.

[30] I.D. Reva, S.G. Stepanian, L. Adamowicz, R. Fausto, Chem. Phys. Lett. 374 (2003) 631. 